\title{
Photoacoustic Imaging for Management of Breast Cancer: A Literature Review and Future Perspectives
}

\author{
A. Prabhakara Rao ${ }^{1, * \mathbb{C}}$, Neeraj Bokde ${ }^{2, * \mathbb{D}}$ and Saugata Sinha ${ }^{1}$ \\ 1 Department of Electronics and Communication Engineering, Visvesvaraya National Institute of Technology, \\ Nagpur 440010, India; saugata.sinha@ece.vnit.ac.in \\ 2 Department of Engineering-Renewable Energy and Thermodynamics, Aarhus University, \\ 8000 Aarhus, Denmark \\ * Correspondence: prabhakar.amarana@gmail.com (A.P.R.); neerajdhanraj@eng.au.dk (N.B.)
}

Received: 23 December 2019; Accepted: 20 January 2020; Published: 21 January 2020

\begin{abstract}
In this review article, a detailed chronological account of the research related to photoacoustic imaging for the management of breast cancer is presented. Performing a detailed analysis of the breast cancer detection related photoacoustic imaging studies undertaken by different research groups, this review attempts to present the clinical evidence in support of using photoacoustic imaging for breast cancer detection. Based on the experimental evidence obtained from the clinical studies conducted so far, the performance of photoacoustic imaging is compared with that of conventional breast imaging modalities. While we find that there is enough experimental evidence to support the use of photoacoustic imaging for breast cancer detection, additional clinical studies are required to be performed to evaluate the diagnostic potential of photoacoustic imaging for identifying different types of breast cancer. To establish the utility of photoacoustic imaging for breast cancer screening, clinical studies with high-risk asymptomatic patients need to be done.
\end{abstract}

Keywords: photoacoustic imaging; optoacoustic imaging; breast imaging; breast cancer detection; breast phantom imaging; animal breast imaging; in vivo breast imaging; breast cancer screening; breast cancer diagnosis

\section{Introduction}

Globally, the number of breast cancer cases was largest among the different types of cancers, considering male and female populations together, and it was the leading cause of cancer-induced deaths among women in 2015 [1]. Breast cancers are classified as non-invasive breast cancer and invasive breast cancer (IBC). Non-Invasive breast cancers are those which do not spread, and comprise ductal carcinoma in situ (DCIS) and lobular carcinoma in situ (LCIS). Invasive or infiltrating breast cancers can spread to other parts of the body, and they are comprised of invasive ductal carcinoma (IDC) and invasive lobular carcinoma (ILC) [2].

In the year 2015 alone, worldwide, 523,000 women died because of breast cancer, while in the previous 16 years (2005-2015) breast cancer cases had increased by 43\% [1]. For American women, it is the second leading cause of deaths due to cancer [3,4]. The American Cancer Society estimated that the number of new female IBC cases in the United States for 2019 would be 268,600 in addition to 62,930 in situ cases, and also estimated that the number of deaths due to female breast cancer would be 41,760 [5].

Early detection of breast cancer can be an effective strategy for reducing the number of breast cancer-induced deaths [6]. For successful treatment, breast cancer should be detected at an early stage when it is small and yet to spread. For early detection, a reliable screening technique for detecting breast cancer in asymptomatic women was required. Breast cancers that are detected successfully 
during screening tests are more likely to be smaller and are still confined to the breast. The two most important parameters for the successful diagnosis of a breast cancer patient are the size of breast cancer and how far it has spread [7]. Screening is performed on a targeted population with asymptomatic patients who are evaluated for cancer yet to be detected, or precancer. During screening, it is expected that most of the population will not have the disease. Diagnosis is performed on patients who have some symptoms of breast cancer, such as a lump in the breast, breast pain, nipple discharge, etc. Both early diagnosis and screening are important components of a comprehensive cancer control but they differ in parameters, such as resources, as well as infrastructure requirements, impact, and cost. The target population in screening is 50-100 times the number of participants in early diagnosis. Screening involves mostly in situ cases and a very few invasive cases, whereas in early diagnosis most of the cases are invasive [8]. Diagnostic tests are more involved, time-consuming, and expensive than screening tests and are performed to determine the size and location of abnormalities. In the case of breast cancer, sometimes diagnosis also involves evaluation of surrounding tissues and lymph nodes [9].

There are some commonly available medical imaging modalities, such as X-ray mammography, ultrasound (US) imaging, and magnetic resonance imaging (MRI), which are used separately or in combination for the screening of the breast cancer. For an asymptomatic patient, the commonly used diagnosis protocol using imaging is to refer the patient for a biopsy procedure to confirm the breast cancer diagnosis if the patient comes up with a suspected X-ray mammogram and US image [10]. X-ray mammography, in addition to possessing ionization hazards, has limited sensitivity specifically for women under 50 [11-13]. Although the American Cancer Society recommends regular breast cancer screening with X-ray mammograms for women in certain age groups, it recommends using MRI along with X-ray mammogram for breast cancer detection. For imaging dense breast tissues which are generally found in younger women, $X$-ray mammogram cannot be used $[12,14,15]$. US imaging is another imaging modality used for imaging breast cancer. When X-ray mammography produces conflicting inference with that of the US image, MRI is done before referring the patient for a biopsy procedure [10]. Due to low soft tissue contrast and strong operator dependency, US imaging is not a very efficient tool for breast cancer detection. Both the US image and X-ray mammogram provide morphological information related to the breast [10]. As in the early stages, breast cancer does not produce significant morphological changes, and X-ray mammogram and US imaging may not be suitable for early detection of breast cancer.

MRI is a noninvasive imaging modality that does not involve any ionizing radiation. It is capable of providing better sensitivity than X-ray mammogram or US imaging for breast cancer detection [15]. Imaging of the dense breast tissues and breast implants can be successfully accomplished using MRI while they cannot be performed using X-ray mammogram $[14,16,17]$. MRI plays an important role as a diagnostic tool especially in detecting multifocal and contralateral or multicentric breast cancers, in detecting occult primary breast cancer, which is common in patients with axillary lymph node metastasis, and also in monitoring neoadjuvant chemotherapy and identifying the recurrences $[14,16,18,19]$. It provides good spatial resolution and it may also be useful in indicating whether or not the breast cancer has spread into the chest wall. The quality of the MRI depends on the patient's hormonal status $[20,21]$ so it requires contrast agents. It is an expensive detection method and consequent inaccessibility is its major drawback. It takes a longer time compared to mammography. Apart from high cost and longer imaging time, MRI also has some other limitations such as low specificity and high false positive rates $[15,17,18,22]$. In the preoperative setting, this low specificity of MRI leads to diagnostic ambiguity, which may lead the surgeons to perform more extensive breast cancer operations. This causes no improvement in overall survival rates and also fails to reduce the local recurrence rates [15]. Although MRI is generally considered to be more accurate than X-ray mammograms, occasionally it may fail to detect breast cancer, particularly involving calcium depositions for a particular patient, which can be detected by X-ray mammography [23,24]. Due to factors such as occasional low specificity, high cost, the requirement of contrast agents, unacceptability for pregnant women, 
and patients with metal implants, MRI is not a suitable imaging modality for early detection of breast cancer $[10,14,18,25,26]$.

Angiogenesis, i.e., the production of new blood vessels, is a primary hallmark for detection of malignant lesions [27-29]. This hallmark can be detected by probing the breast with optical radiation at the NIR (near-infrared) region. However, pure optical imaging suffers from degrading spatial resolution with an increase of the depth in soft tissue, whereas photoacoustic (PA) imaging is capable of maintaining good spatial resolution inside the tissue [30]. PA imaging is an emerging hybrid imaging modality based on the PA effect. In the PA effect, after absorbing a short duration (nanosecond) pulse laser light, the light absorbing material (soft tissue) generates US waves [31,32]. The absorbed light energy creates localized heating inside the light-absorbing material which, in turn, produces an increase of pressure and this pressure is released in the form of broadband US waves [33]. As it uses light to probe the tissue, PA imaging can determine functional information in terms of optical properties of the tissue which change with the change of the distribution of blood vessels, as well as other chromophores (light-absorbing tissue elements) inside the tissue. At the same time, since it detects US waves which do not scatter much inside soft tissue, PA images do not suffer from the problem of poor spatial resolution deep inside the soft tissue. The low-intensity non-ionizing laser light used in PA imaging poses no health hazard, unlike the ionizing radiation associated with X-ray screening mammography. Another advantage with PA imaging is that since the receiving technology is the same for both PA and US imaging, the already commercially available US imaging system can be modified to produce a dual mode PA-US imaging system. This dual mode system can be used to acquire co-registered PA and US images of the breast, which can be potentially applied for early detection of breast cancer. Using the morphological cues provided by the US images, it is possible to localize a malignant lesion in the early stage which has already been detected by the PA image. Photoacoustic (PA) imaging systems are broadly classified into two categories, namely PA tomography and PA microscopy [34]. In PA tomography, a large-diameter pulsed laser beam is used to irradiate the tissue surface, and different US transducer arrays (planar, linear, spherical, hemispherical, circular, cylindrical) are used to scan the tissue/organ along different trajectories to collect the PA signals generated by the tissue. Grayscale 2D PA images (B scan, C scan) are formed using specific reconstruction algorithms with the acquired PA data. A schematic of the PA tomography (PAT) system for breasts cancer detection is shown in Figure 1, which illustrates the process of PA signal generation from the breast and the process of generating grayscale PA images from the acquired PA signals.

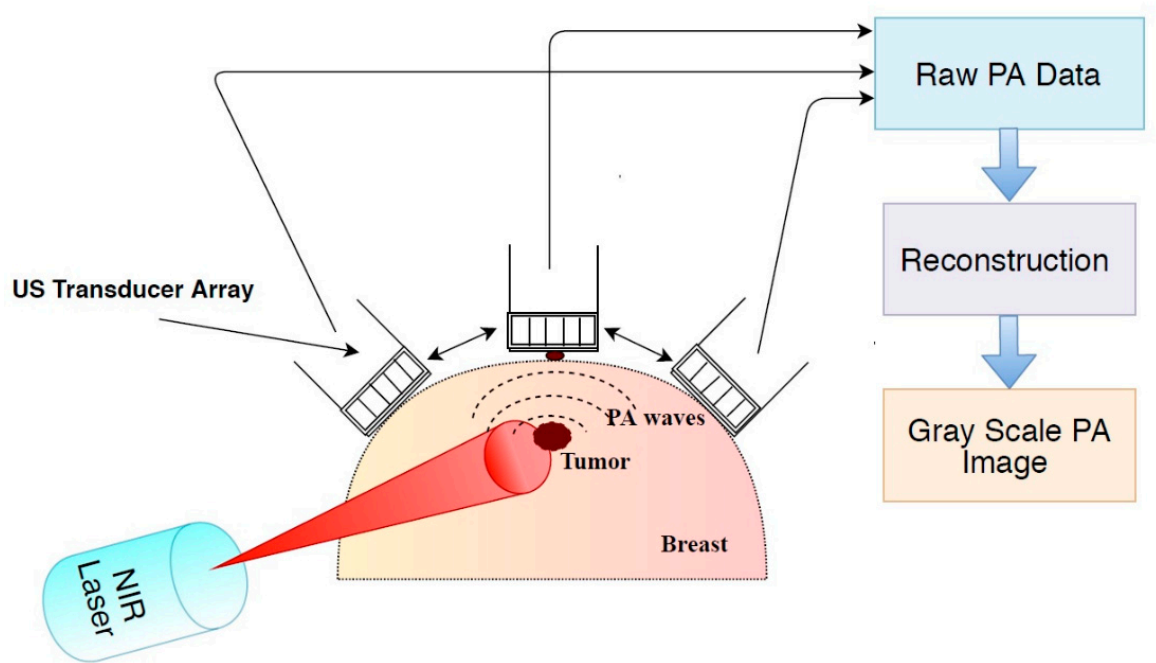

Figure 1. Schematic of the PAT system for breast cancer detection.

Cylindrical, circular, spherical, and hemispherical US arrays require access to major portions around the region to be imaged, so, barring a handful of cases, like small animal imaging or breast 
cancer imaging, these arrays are not suitable for in vivo imaging. On the other hand, planar and linear US arrays can be used widely for in vivo imaging as they can work with restricted access. In the case of in vivo breast imaging, it is not possible to use spherical US arrays, as they require access to the complete region around the organ to be imaged. In such cases, where there is restricted access, planar [35,36], and linear [37,38] US arrays can be used. However, hemispherical $[39,40]$ US arrays were used by some researchers for breast imaging. The reconstruction algorithms are primarily different variants of back projection algorithms which are used to recover the spatially-varying PA signals generated at each location inside the tissue. In PA microscopy, the tissue/organ is illuminated using a tightly focused beam, and the PA signal is detected generally using focused single element US transducer. The tissue/organ is scanned along certain trajectories by laser beam along with the US transducer and the PA signals acquired by the US transducer are used directly to form the 2D PA images [41]. Using contrast agents, both PA imaging contrast and imaging depth can be significantly improved. In cancer detection, there are two strategies used to navigate contrast agents to the target, a passive and an active targeting strategy. In passive targeting, the physical properties of the tumor, such as enhanced permeation and retention (EPR) effect, are utilized. This facility is more prominent in xenograft tumor models than in human patients [42-45]. In the active targeting strategy, molecules which have the ability to selectively bind to a particular target are used. These binding molecules or targeting moieties are conjugated with the contrast agents before administration to the organism [46]. Researchers performed animal studies using dyes, such as Indocyanine green (ICG), Methylene Blue, Evans blue, and different nanomaterials for breast cancer detection, as well as sentinel lymph node (SLN) detection.

This review paper attempts to present an in-depth analysis of the research performed so far towards the development of PA imaging technology for breast cancer detection. In some earlier research articles [25,47], comparative analysis of the system parameters of different PA imaging system was presented. In a review article, Menke [48] focused on the clinical studies performed with human patients using the prototypes developed until 2014 by different research groups and gave a comparative analysis of system configuration of different prototypes for breast cancer imaging, as well as their performance parameters. In another review article about the clinical application of PA imaging, Zackrisson et al. [49] summarized the recent advances of PA imaging for breast cancer based on the results of clinical studies of various research groups. Valluru et al. [50] presented a review article containing the state-of-the-art PA imaging techniques, highlighting the clinical applications of PA imaging techniques for different types of cancers. Summarizing various preclinical studies related to brain, breast, lung, prostate, thyroid, and skin cancers, Gargiulo et al. [51] described the preclinical applications of PA imaging for cancer detection using endogenous and exogenous contrast agents. Steinberg et al. [34], presented various clinical studies performed using PA imaging. In some recent review articles [52,53], the state of the art PA imaging systems, as well as the clinical studies for breast cancer diagnosis using PA imaging, were reported.

Translation of any medical imaging system into clinical practice depends on its progressive development beginning with a proof of concept stage where the system is tested on numerical phantoms. Following successful proof of concept studies, the system will be tested using phantoms mimicking human tissue and in vivo animal studies. In the final stage, the system will be evaluated in carefully-designed clinical trials involving human patients. In each stage, based on the findings of the research studies, the system is modified and fine-tuned to accommodate the requirements of its ultimate usage in a clinical environment. Our review gives a complete picture of the evolution of photoacoustic (PA) imaging for breast cancer management based on the pre-clinical and clinical studies performed by several research groups. Specifically, for deep tissue applications, endogenous contrast provided by PA imaging systems is not sufficient to detect the malignancy. To see the potential of PA imaging for deep breast imaging applications, its performance has to be evaluated using exogenous contrast agents. Animal studies were performed using various contrast agents, such as dyes and nanoparticles for breast cancer detection. Our review presents the results of these animal studies using 
contrast agents for breast cancer detection and detection of sentinel lymph nodes (SLNs). In order to understand the potential of PA imaging using contrast agents, such as dyes and nanoparticles, in detecting SLNs, a summary of different studies reporting the utility of PA imaging with contrast agents for detecting SLNs is presented. This gives the readers a complete picture of the development of PA imaging systems for breast cancer management. The recent review articles $[48,52]$ only focused on clinical PA imaging studies which did not include phantom studies, animal studies using endogenous and exogenous contrast agents (dyes and nanoparticles) for breast cancer detection as well as SLN detection, ex vivo studies with human breast tissue samples.

To understand the potential of PA imaging, its performance needs to be compared with the conventional imaging techniques for breast cancer detection. This review presents a detailed comparative analysis of PA imaging systems with the conventional imaging systems used for breast cancer detection based on the clinical results reported by different research groups. Spectroscopic PA imaging can be used to measure the concentration of different light-absorbing elements, like oxyhemoglobin, de-oxy hemoglobin, melanin, lipid, etc., present in soft tissue. This will enable us to estimate the oxygen saturation, total hemoglobin, lipid content, etc., in order to differentiate between different breast pathologies (normal, hyperplasia, DCIS and IBC). In order to explore the potential of spectroscopic PA imaging systems, this review presents a summary of spectroscopic PA imaging studies performed by different research groups. From the literature, it was found that PA imaging can be used to monitor the efficacy of anti-cancer treatments, such as chemotherapy or molecular targeting therapies, through changes in the PA images of tumor-related blood vessels. Few studies reported the potential of PA imaging for breast cancer treatment monitoring and these reported results are summarized in this review. Along with providing a detail comparative analysis of the system parameters of the different PA imaging systems used by the different research groups until 2019, this review attempts to present the clinical evidence in support of using PA imaging for breast cancer detection. Highlights of this review are summarized in Table 1.

Table 1. Highlights of the presented review.

Based on the study results reported by various research groups beginning from 1997 to 2019, this review provides:

- A complete picture of the evolution of photoacoustic (PA) imaging for breast cancer management.

- A detailed comparative analysis of PA imaging with other conventional imaging techniques used for breast cancer detection.

- Answers to the issues related to the role and utility of PA imaging technology for the detection and diagnosis of breast cancer.

- The utility of spectroscopic PA imaging studies to differentiate between different breast pathologies.

- The potential of PA imaging technology for breast cancer treatment monitoring.

This review paper is organized in the following manner: 'Methods' describes the list of various databases for the literature search, the search keywords and search period. 'Results' summarizes the results of the search mentioned in Methods section, and it provides a comprehensive overview of the research work performed by different research groups towards the utilization of PA imaging technology for the management of breast cancer. It is divided into four subsections containing the details of phantom studies, animal studies, ex vivo and in vivo studies with human patients, while animal studies are further divided into groups containing the results of studies with endogenous and exogenous contrast agents (including imaging of SLNs). 'Discussion' compares the configuration details as well as system parameters of different PA imaging systems developed by various research groups. It also provides a detailed discussion on the potential of the clinical use of PA imaging technology for breast cancer detection relative to the conventional imaging modalities, like US imaging, X-ray mammogram, and MRI, based on the results of in vivo studies conducted so far. The last section, 'Conclusion', highlights future research work, required for the translation of the technology from the laboratory environment to clinical practice. 


\section{Methods}

The initial search was conducted through electronic databases Web of Science, PubMed, IEEE, and Nature. Initially, a search was performed using the keyword 'Breast Imaging' which resulted in a huge number of articles (more than 125,917) (Table 2). To make the search more targeted, the keywords 'Photoacoustic Imaging', 'Optoacoustic Imaging', and the phrases 'Photoacoustic Imaging for breast cancer', 'Optoacoustic imaging for breast cancer' were used. During the initial search, it was found that Esenaliev et al. [54] pioneered the concept of applying PA imaging for breast cancer detection, and they conducted a phantom study to support the concept. All searches were conducted for a time period of 1997-2019.

Table 2. Literature search statistics.

\begin{tabular}{|c|c|c|c|c|c|c|c|c|c|c|}
\hline \multirow{2}{*}{$\begin{array}{l}\text { Electronic } \\
\text { Database }\end{array}$} & \multicolumn{2}{|c|}{ Web of Science [55] } & \multicolumn{2}{|c|}{ PubMed [56] } & \multicolumn{2}{|c|}{ IEEE [57] } & \multicolumn{2}{|c|}{ Nature [58] } & \multirow{2}{*}{ Total } & \multirow{2}{*}{ Remarks } \\
\hline & Phrase1 & Phrase2 & Phrase1 & Phrase2 & Phrase1 & Phrase2 & Phrase1 & Phrase2 & & \\
\hline Number of Articles & 424 & 128 & 190 & 32 & 38 & 9 & 103 & 30 & 924 & $\begin{array}{l}\text { Initial } \\
\text { Search }\end{array}$ \\
\hline $\begin{array}{l}\text { PA/OA for other } \\
\text { cancers }\end{array}$ & 79 & 30 & 23 & 1 & 7 & 2 & 20 & 5 & 167 & \\
\hline $\begin{array}{l}\text { BC with other } \\
\text { imaging system }\end{array}$ & 24 & 2 & 5 & 0 & 2 & 0 & 5 & 0 & 38 & Excluded \\
\hline Others & 19 & 7 & 1 & 0 & 2 & 0 & 45 & 10 & 84 & \\
\hline $\begin{array}{l}\text { Remaining } \\
\text { Articles }\end{array}$ & \multicolumn{8}{|c|}{ Articles from initial search (924)—Articles excluded (431) } & 493 & \\
\hline
\end{tabular}

\section{Results}

The search of the databases mentioned above yielded a total of 924 research articles. After going through the abstracts of these articles, a total of 167 articles which contained the results of studies related to PA imaging of cancers other than breast were excluded. Around 38 articles which were related to breast cancer detection using imaging modalities other than PA imaging were excluded. A total of 142 articles related to the PA imaging systems without application to any cancer and another 84 articles which were neither related to PA imaging nor breast cancer were excluded. The detailed search statistics of each of the databases were summarized in Table 2. The duplicates were eliminated from the remaining articles. Among the remaining, articles reporting the results of those studies which were approved by either an ethics committee or the institutional review board and had informed consent wherever appropriate, were considered. Finally, we selected 66 articles, which contained the results of the studies related to breast cancer detection using PA imaging for this review. Among these 66 articles, 20 articles focused on the PA imaging of SLNs.

\subsection{Description of Studies}

It was found from the literature search that a few research groups have been working on utilizing PA imaging for breast cancer detection for the last two decades. The performance of their PA imaging systems for breast cancer detection has been evaluated progressively, beginning with the study on breast tissue-mimicking phantoms. Once the phantom studies were successful, the research groups further proceeded to perform ex vivo as well as in vivo studies with animals. Eventually, some of the research groups performed clinical studies with human patients and reported their observations comparing their results with that of other clinically approved medical imaging modalities like X-ray mammogram, US 
imaging, and MRI. Prior to proceeding in vivo studies with human patients, some groups performed ex vivo studies with freshly excised breast tissue specimens obtained after mastectomy. This review paper tries to provide a comprehensive account of the chronological, as well as the technological progress of the research related to PA imaging for the early detection of breast cancer.

\subsubsection{Phantom Studies}

It was found from the literature that during 1997-2016, several research groups have performed phantom studies to understand the potential of PA imaging for breast cancer detection. In 1997, the research group headed by Oraevsky [54] performed the first phantom study to evaluate the capability of PA imaging for breast cancer detection. In 2005, research groups led by Manohar [59] and Wang [60] performed phantom studies using PA imaging for breast cancer detection. Later on, other research groups performed phantom studies using PA imaging for breast cancer detection. Details of these studies were given below.

Esenaliev et al. [54] reported the usefulness of photoacoustic imaging for breast cancer detection using a phantom study. They successfully visualized small spherical tumor phantoms of $2 \mathrm{~mm}$ diameter which are located within the bulk collagen gels at a depth of up to $60 \mathrm{~mm}$ within breast phantoms of $100 \mathrm{~mm}$ thick. Oraevsky et al. [61] built the first PA imaging system-laser optoacoustic imaging system (LOIS) - which could be used for breast cancer detection in a clinical environment. This imaging system was operated at a single wavelength $1064 \mathrm{~nm}$, contained a 12-element linear array US transducer. Using this system, gel spheres of $8 \mathrm{~mm}$ diameters were detected at a depth of $50 \mathrm{~mm}$ inside breast tissue-mimicking phantom. Using LOIS-02, in which the linear transducer array of 12 elements of the LOIS system was replaced by a 32 element arc-shaped transducer array, Andreev et al. [62] successfully detected tumors of size $2 \mathrm{~mm}$ into the $6 \mathrm{~cm}$ deep breast tissue-mimicking phantoms. The Bandwidth of the US transducer was in the range from $20 \mathrm{kHz}$ to $2 \mathrm{MHz}$. The in-depth resolution and lateral resolution of this system were $0.4 \mathrm{~mm}$ and $1-2 \mathrm{~mm}$ depending on the position of the tumor relative to the transducer array. In another modification of the LOIS system, Oraevsky et al. [63] used a 32-element arc-shaped polyvinylidene fluoride (PVDF) transducer array for PA wave detection. This system successfully detected blood vessels of $2 \mathrm{~mm}$ (diameter) at a depth of $7.5 \mathrm{~cm}$ inside the breast tissue-mimicking phantoms. Oraevsky et al. [64] performed another phantom study with LOIS system in which PA images were acquired at two different wavelengths, $757 \mathrm{~nm}$ and $1064 \mathrm{~nm}$, and the acquired PA data were used to calculate oxygen saturation $\left(\mathrm{SO}_{2}\right)$ of blood. Ermilov et al. [65] developed a new version of LOIS system, named LOIS-128 in which a linear US transducer array of 128 elements with a system cutoff frequency of $4 \mathrm{MHz}$ was used to detect PA waves. They claimed that LOIS-128 was capable of continuous planar imaging of small tumors (less than $1 \mathrm{~cm}$ ) at depths of more than $6 \mathrm{~cm}$ inside the tissue. Ermilov et al. [66] developed and used the LOIS-64 system which contained US transducers in the form of an arc-shaped array of 64 elements with bandwidth up to $2.5 \mathrm{MHz}$ to acquire PA images of breast phantoms and achieved a spatial resolution of $0.5 \mathrm{~mm}$.

Manohar et al. [59] developed a PA mammography system, 'Twente PAM', which contained a laser light delivery system at $1064 \mathrm{~nm}$ and a flat US detector matrix of 590 elements. The central frequency of US detector was $1 \mathrm{MHz}$ with a bandwidth in the range from $0.45 \mathrm{MHz}$ to $1.78 \mathrm{MHz}$. This system was capable of imaging inhomogeneities of $2 \mathrm{~mm}$ diameter at depths up to $32 \mathrm{~mm}$ with an axial resolution of $3.5 \mathrm{~mm}$. Using Twente PAM, Jose et al. [67] imaged breast tumor vasculature inside Polyvinyl Alcohol (PVA) breast phantom. The lateral resolution of the US detector was in the range $2.5 \mathrm{~mm}$ to $3.9 \mathrm{~mm}$ and an axial resolution was in the range from $2.3 \mathrm{~mm}$ to $3.9 \mathrm{~mm}$. Xia et al. [68] developed a 3D photoacoustic full breast tomography system and evaluated its performance using tissue-mimicking phantoms. US transducer was a linear array of 8 elements with $0.6 \mathrm{MHz}$ center frequency and $75 \%$ bandwidth. The field of view (FOV) and penetration depth of the system were $170 \times 170 \times 170 \mathrm{~mm}$ and $40 \mathrm{~mm}$, respectively, while its spatial resolution was $2 \mathrm{~mm}$ in XY plane and $6 \mathrm{~mm}$ along the $\mathrm{Z}$ axis. 
Combining thermoacoustic (TA) imaging with PA imaging, Ku et al. [60] developed a dual mode imaging system to detect lesions and objects deeply situated in biological tissues. Their PA imaging system contained four US transducers with different central frequencies of $2.25 \mathrm{MHz}, 3.5 \mathrm{MHz}, 5 \mathrm{MHz}$, and $10 \mathrm{MHz}$ and all with bandwidths ranging from $50 \%$ to $80 \%$ of the corresponding central frequencies. Using PA images acquired at $1064 \mathrm{~nm}$ with a $3.5 \mathrm{MHz}$ cylindrically focused US transducer, their system was able to detect blood objects embedded in chicken breast muscle up to a depth of $5 \mathrm{~cm}$. Pramanik et al. [69] developed a multimodal breast cancer imaging system containing TA and PA imaging systems. PA images of breast-tissue mimicking phantoms were acquired at $1064 \mathrm{~nm}$ using two US transducers of $13 \mathrm{~mm}$ and $6 \mathrm{~mm}$ diameter active area. The central frequency of these US transducers was $2.25 \mathrm{MHz}$, and their resolution was reported to be approximately $0.7 \mathrm{~mm}$. Ke et al. [70] developed a tri-modality imaging system by integrating PA and TA imaging in a modified commercial ultrasound scanner, and it was tested on a chicken breast tissue. PA images were acquired at $650 \mathrm{~nm}$ using a US transducer phased array consisting of 80 elements with a frequency band of 1 to $5 \mathrm{MHz}$. Maximum penetration depth achieved with this system was $6.6 \mathrm{~cm}$ at a signal to noise ratio (SNR) nearly equal to $24 \mathrm{~dB}$. The axial resolution of the PA imaging system was $640 \mu \mathrm{m}$, and the lateral resolution was in the range from $720 \mu \mathrm{m}$ to $2 \mathrm{~mm}$, whereas the best elevation resolution achieved with this system was $3.5 \mathrm{~mm}$.

Ye et al. [71] developed a 3D PA imaging system in line confocal mode which used a 64 element linear US transducer array with a central frequency of $7.5 \mathrm{MHz}$ and $70 \%$ bandwidth to detect the PA signals. Using a phantom containing carbon points, they found an improved spatial resolution of the PA imaging system when it was operated in the confocal mode.

$X_{i}$ et al. [72] combined PA imaging system with diffuse optical tomography (DOT) system to develop a hybrid imaging system for breast cancer detection. US transducer consists of a ring-shaped array of 64 elements with frequency response from $380 \mathrm{KHz}$ to $1.48 \mathrm{MHz}$, and maximum frequency response was up to $2 \mathrm{MHz}$. They reported that the spatial resolution of the PA imaging system used in this study was $\sim 0.5 \mathrm{~mm}$. This system was tested on a tumor (removed from a rat bearing a 4T1) of $3.5 \mathrm{~mm}$ in radius embedded in the phantom background. The absorption image of PA imaging system estimated the size of the tumor as $3 \mathrm{~mm}$ in radius.

Kruger et al. [73] developed a photoacoustic imaging system for breast cancer with a spherical detector aperture along which 512 US detectors were arranged. The center frequency of the US detector was $2 \mathrm{MHz}$ with a $70 \%$ bandwidth. Using suitable phantoms, they showed that the imaging system could clearly visualize a target up to a depth of $53 \mathrm{~mm}$ inside tissue with a minimum spatial resolution equal to $0.42 \mathrm{~mm}$

Bharathiraja et al. [74] employed a photoacoustic tomography system at $800 \mathrm{~nm}$ wavelength using a $10 \mathrm{MHz}$ single element focused US transducer to image astaxanthin-mediated gold nanoparticles (Atx-AuNPs)-treated breast cancer cells in a gelatin-based phantom mimicking biological tissue.

Details of various materials used to mimic breast tissue, tumors/blood vessels/targets in phantoms of the above phantom studies were summarized in Table 3.

Table 3. Details of materials used for breast tissue, tumor and blood vessels in phantom studies.

\begin{tabular}{ccc}
\hline Phantom Study & $\begin{array}{c}\text { Materials Mimicking Breast } \\
\text { Tissue }\end{array}$ & $\begin{array}{c}\text { Materials Mimicking Tumor/Blood } \\
\text { Vessel/Target }\end{array}$ \\
\hline Esenaliev et al. [54] & $\begin{array}{c}10 \% \text { gelatin (bulk collagen gels) } \\
1064 \mathrm{~nm}_{\left(\mu_{\mathrm{a}}=0.11 \mathrm{~cm}^{-1},\right.}^{\left.\mu_{\mathrm{s}}^{\prime}=2.92 \mathrm{~cm}^{-1}\right)}\end{array}$ & $\begin{array}{c}\text { Gel spheres colored with the bovine } \\
\text { hemoglobin }\left(\mu_{\mathrm{a}}=0.75 \mathrm{~cm}^{-1}\right)\end{array}$ \\
\hline Oraevsky et al. [61] & $10 \%$ gelatin $\left(\mu_{\mathrm{a}}=0.13 \mathrm{~cm}^{-1}\right)$ & $\begin{array}{c}\text { Gel spheres colored with the bovine } \\
\text { hemoglobin }\end{array}$ \\
\hline Andreev et al. [62] & Gelatin & $\begin{array}{c}\text { Gel spheres colored with the bovine } \\
\text { hemoglobin }\left(\mu_{\mathrm{a}}=1.0 \mathrm{~cm}^{-1}\right)\end{array}$ \\
\hline Oraevsky et al. [63] & Gelatin & $\begin{array}{c}\text { Blood vessels filled with rat blood }\left(\mu_{\mathrm{a}} \text { varies }\right. \\
\left.\text { from } 0.8 \text { to } 4.0 \mathrm{~cm}^{-1}\right)\end{array}$ \\
\hline
\end{tabular}


Table 3. Cont.

\begin{tabular}{|c|c|c|}
\hline Phantom Study & $\begin{array}{c}\text { Materials Mimicking Breast } \\
\text { Tissue }\end{array}$ & $\begin{array}{c}\text { Materials Mimicking Tumor/Blood } \\
\text { Vessel/Target }\end{array}$ \\
\hline Oraevsky et al. [64] & $10 \%$ gelatin $\left(\mu_{\mathrm{a}}=0.13 \mathrm{~cm}^{-1}\right)$ & $\begin{array}{l}\text { Polyethelene tubes filled with the blood of } \\
\text { sheep }\left(\mu_{\mathrm{a}} \text { in the range of } 0.45 \text { to } 1.0 \mathrm{~cm}^{-1}\right) \text {. }\end{array}$ \\
\hline Ermilov et al. [65] & $\begin{array}{l}\text { Polyvinyl chloride-plastisol } \\
\text { (PVCP) }\end{array}$ & Pencil leads \\
\hline Ermilov et al. [66] & $\begin{array}{l}\text { India ink dissolved in aqueous } \\
\text { milk solution }\end{array}$ & $\begin{array}{l}\text { A thin-wall rubber shell filled with India ink } \\
\text { dissolved in aqueous milk solution }\end{array}$ \\
\hline Manohar et al. [59] & Poly vinyl alcohol (PVA) gel & Dyed, rigid PVA gel spheres \\
\hline Jose et al. [67] & Intralipid, PVA & $\begin{array}{l}\text { A silicon rubber tube filled with flowing } \\
\text { human blood and dyed, rigid PVA gel spheres }\end{array}$ \\
\hline Xia et al. [68] & Agar/intralipid gel & $\begin{array}{l}\text { Plastic tube filled with agar gel and spherical } \\
\text { objects made of agar gel }\end{array}$ \\
\hline Ku et al. [60] & Chicken breast muscle & Raw blood in $1.5 \mathrm{~mm}$ diameter tube \\
\hline Pramanik et al. [69] & Porcine fat & $\begin{array}{l}\text { water-based agar gel } 2 \% \text { agar, } 2 \% \text { salt and } \\
\text { 96\% water): clear gel/gel mixed with black } \\
\text { India ink }\end{array}$ \\
\hline Ke et al. [70] & Chicken breast & $\begin{array}{c}\text { Low-density polyethylene (LDPE) tubes filled } \\
\text { with either oxygenated bovine blood or } \\
\text { methylene blue dye }\end{array}$ \\
\hline Ye et al. [71] & $\begin{array}{l}13 \% \text { gelatin, } 12.5 \% \text { milk, } \\
\text { and } 74.5 \% \text { water }\end{array}$ & Carbon points \\
\hline Xi et al. [72] & Intralipid + India ink & Thin metal wires and ex-vivo tumor tissue \\
\hline Kruger et al. [73] & $\begin{array}{l}\text { Carbon/graphite fiber embedded } \\
\text { in agar }\end{array}$ & $\begin{array}{l}\text { Point absorber (a small spot of ink placed on } \\
\text { the tip of a clear, thin polyethylene thread) }\end{array}$ \\
\hline Bharathiraja et al. [74] & Gelatin & $\begin{array}{l}\text { Astaxanthin-mediated gold nanoparticles } \\
\text { (Atx-AuNPs)-treated breast cancer cells }\end{array}$ \\
\hline
\end{tabular}

\subsubsection{Animal Studies}

Animal studies performed by some research groups without using any contrast agents were described here under the subsection 'Endogenous contrast agents'. In 2009, the research group headed by Manohar [67] performed PA imaging studies on animals for breast cancer detection without using any exogenous contrast agents, and then after five years, the research group of Wilson et al. [75] performed spectroscopic PA imaging studies on animals for breast cancer detection. Some studies on animals by different research groups involving external contrast agents were described under the subsection 'Exogenous contrast agents' which also includes the studies performed on animals with external contrast agents to detect SLNs. Many animal studies were performed by the research group headed by Wang during the period from 2008 to 2012 using PA imaging for SLN mapping using dyes and nanomaterials. Later on, during 2013-2017, we found similar studies were performed by other research groups. During the period 2013-2017, several research groups performed PA imaging studies on animals with exogenous contrast agents such as nanomaterials and dyes for breast cancer detection.

\section{Endogenous Contrast Agents}

Jose et al. [67] used the Twente PA Imaging system at the $1064 \mathrm{~nm}$ wavelength on a rat model to visualize the vasculature development from the early stages of tumor growth. They showed that using PA imaging, the tumor neovascularization could be monitored without sacrificing the animal, which established PA imaging as a promising new tool in tumor angiogenesis research. Wilson et al. [75] performed in vivo spectroscopic PA imaging with a transgenic mouse model to evaluate the feasibility of differentiating among different breast pathologies (normal, hyperplasia, DCIS, IBC), in terms of oxygen saturation, total hemoglobin content and lipid content. Spectroscopic PA imaging of this study 
resulted in the increased oxygen saturation of hyperplasia (50.6\%), DCIS (43.0\%), and IBC (46.2\%) as compared to normal glands (35.5\%), whereas both the total hemoglobin and lipid content significantly decreased with advancing histology.

\section{Exogenous Contrast Agents}

Zhang et al. [76] performed PA imaging at $820 \mathrm{~nm}$ in a mouse model to evaluate the feasibility of using non-fluorescent nanodiamond as PA imaging contrast agents for effective HER2 positive breast cancer detection. Balasundaram et al. [77] performed an in vivo PA imaging study with folate-conjugated polymer (CP) dots as contrast agents in xenograft mice models and they demonstrated that after $1 \mathrm{~h}$ of the injection of the contrast agents, the Folate-CP dots accumulated into the tumor site produced fourfold contrast-enhanced PA signal as compared to PA signals produced by CP dots. In an in vivo study with female Balb/c mice, Xiao et al. [78] acquired PA as well as fluorescence images of subcutaneous 4T1 tumors using melanin carbonaceous dots (MCDs) as contrast agents. Xia et al. [79] performed an in vivo PA imaging study with nude mice using biodegradable nanomaterial liposome-encapsulating ammonium bicarbonate $\left(\mathrm{NH}_{4} \mathrm{HCO}_{3}\right)$ as a PA contrast agent. Wilson et al. [80] used antibody indocyanine green (ICG) conjugates in the spectroscopic PA imaging of transgenic murine breast cancer model to distinguish malignant breast tissue and normal breast tissue in mice.

Song et al. [81] initially performed an in vivo PA imaging on a rat model with methylene blue as a contrast agent and identified SLNs from the acquired PA images. They continued this study with gold $(\mathrm{Au})$ nanocages [82] as contrast agents to detect SLNs and observed improved performance over methylene blue, especially these contrast agents eliminated the requirement of invasive axillary staging procedures. In addition to SLN mapping in rats with gold nanorods as contrast agents, they performed spectroscopic PA imaging at three wavelengths $757 \mathrm{~nm}, 807 \mathrm{~nm}$, and $820 \mathrm{~nm}$ [83] to eliminate the need for acquiring control image before the injection of gold nanorods. Further, they performed 3D PA imaging on mice and rats with the use of Evans blue dye [84] and with the acquired high-speed ( $\sim 0.2 \mathrm{~Hz}$ frame rate) 3D PA images, they monitored the dynamic accumulation and clearance of the dye into SLNs. Pramanik et al. [85] performed in vivo PA imaging on a rat model with single-walled carbon nanotubes (SWNT) as a contrast agent and identified SLNs from the acquired PA images. Pan et al. [86] performed PA imaging to detect SLNs using gold nanobeacons (GNBs) as contrast agents in a rodent model. Akers et al. [87] performed in vivo PA imaging on a rat with perfluorocarbon (PFC) nanoparticles loaded with NIR dye PPCy-C8 as a contrast agent and successfully detected lymph nodes. Kim et al. [88] performed in vivo PA imaging on a rat with methylene blue as a contrast agent and visualized SLNs, and accomplished PA image-guided needle insertion into the rat SLN with the use of methylene blue. They continued this study with ICG as a contrast agent [89] and successfully visualized SLNs and lymphatic vessels. Further, they [90] employed a handheld PA probe on a rat with the help of ICG as a contrast agent and, in addition to SLN mapping, they successfully achieved PA image-guided needle-insertion into the axillary lymph nodes of the rat. Erpelding et al. [91] performed in vivo PA imaging on rats with methylene blue as a contrast agent and with the acquired 3D PA images, they dynamically visualized the flow of methylene blue through lymph vessels to the SLNs. Pan et al. [92] performed in vivo PA imaging on a rodent model using PA Tomography (PAT) system with copper neodecanoate nanoparticles as contrast agents and detected SLNs.

Luke et al. [93] performed the real-time US and PA imaging for SLN mapping in a mouse model with the help of silica-coated gold nanoparticles (Si-AuNPs). Grootendorst et al. [94] performed PA imaging on rats with the use of super-paramagnetic iron oxide nanoparticles (Endorem) as a contrast agent. Through PA scans, they visualized the accumulation of these nanoparticles in the lymph nodes, which enabled them to differentiate between normal lymph node and metastatic lymph node. Liu et al. [95] performed in vivo PA imaging on a rat model with copper selenide nanocrystals $\left(\mathrm{Cu}_{2-\mathrm{x}} \mathrm{Se} \mathrm{NCs}\right)$ as a contrast agent and achieved SLN mapping. Koo et al. [96] performed in vivo PA imaging on a rat using their PA imaging system with the use of single-walled carbon nanotubes (SWNTs) conjugated with ICG as a PA contrast agent and clearly visualized SLNs. Lee et al. [97] 
performed in vivo dual-color PA imaging with nano-formulated napthalocyanines (nanonaps) on rats and successfully visualized rat's lymph nodes buried inside $10 \mathrm{~mm}$ thick layer of chicken breast. Yang et al. [98] performed in vitro and in vivo studies using their dual modality PA-US system with carbon nanoparticles added with liquid-gas phase-transition nanodroplets (CNPs) as contrast agents produced excellent contrasts for PA-US imaging. They claimed from the results of this study that these CNPs are highly capable as the theranostic agents in SLNs detection as well as in the therapy of metastatic lymph nodes. Sivasubramanian et al. [99] performed an in vivo study on a rat using a dual PA-US imaging system. The results of their study demonstrated the utility of methylene blue dye in detecting the SLNs, as well as in minimally invasive real-time needle guidance. Cha et al. [100] performed an in vivo study on a rat using a PA imaging system with a silica-coated silver bumpy nanoshell probes as a contrast agent and detected SLNs of rats from the acquired PA images.

Details of animal studies performed using exogenous contrast agents for breast cancer detection as well as SLN detection are summarized in Table 4.

Table 4. Details of studies using exogenous contrast agents.

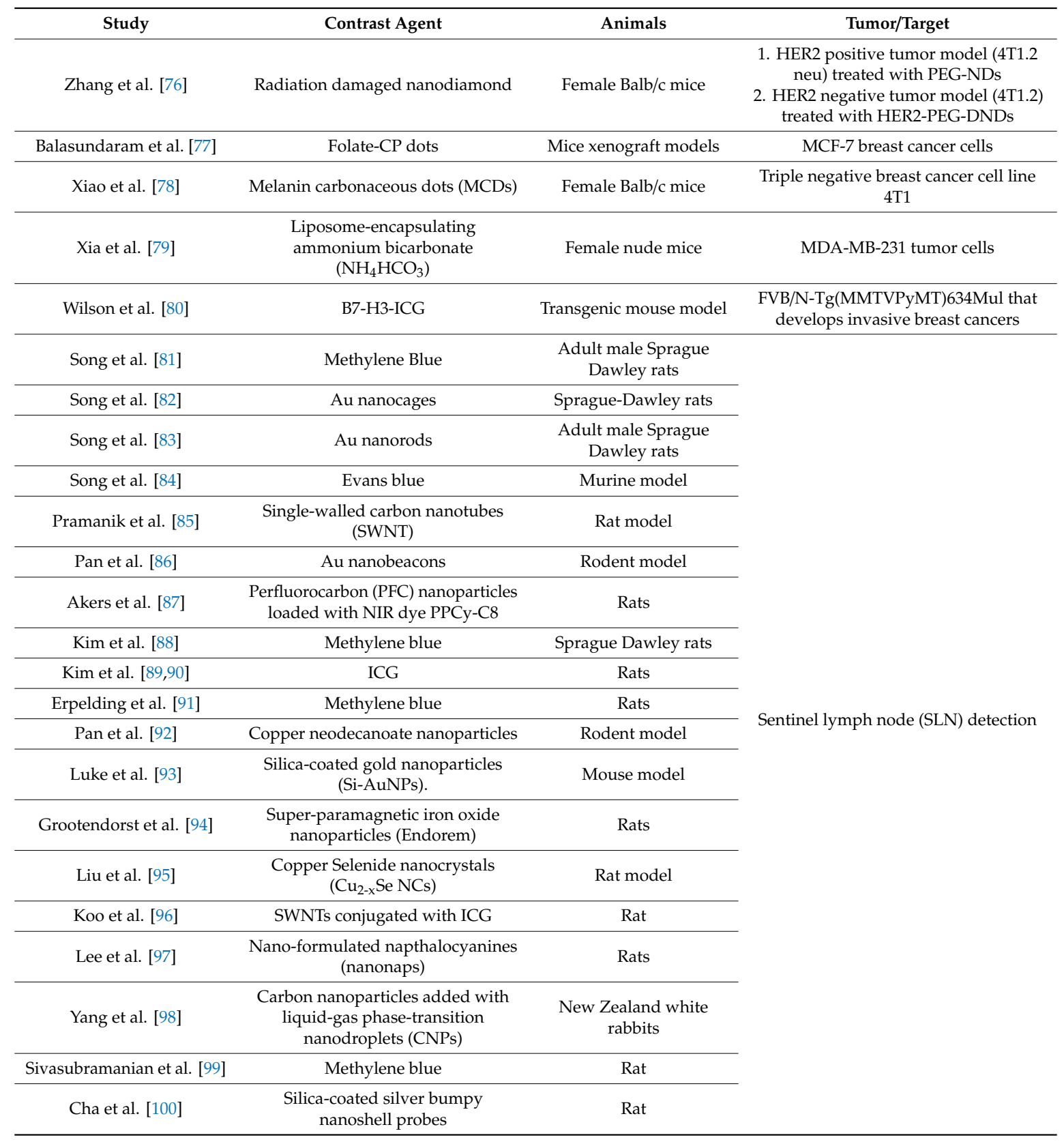




\subsubsection{Ex Vivo Studies}

It was observed from the literature that the research group of G. R. Kim [101] in 2014 and the research group headed by LV Wang [102] in 2017 performed ex vivo studies on excised breast specimens using PA imaging. Kim et al. [101] performed an ex vivo PA imaging study with 21 excised breast specimens at $700 \mathrm{~nm}$ and $800 \mathrm{~nm}$, and they were able to distinguish breast microcalcifications using the PA Images. Wong et al. [102] developed and optimized UV-photoacoustic microscopy of breast tissues and this system could generate images that were comparable in quality to that of conventional histology.

\subsubsection{In Vivo Studies}

In 2007, the research group of Manohar [103] performed in vivo PA imaging studies on human breast cancer patients. Later on, in 2009, the research group headed by Oraevsky [66], performed in vivo studies on human patients using PA imaging for breast cancer detection. During 2012-2015, the largest clinical study on 2105 patients was performed by the research group of Neuschler $[37,38]$ using the dual mode PA-US imaging system (IMAGIO) for breast cancer detection, and in 2016, they performed another in vivo study using the same system for breast cancer detection. In 2018, the research group of Menezes [104,105] reported their study results on 209 patients using the dual mode PA-US imaging system (IMAGIO) for breast cancer detection. In 2013, Kruger's research group [73] performed an in vivo study on human patients using PA imaging. During 2015-2018, the research group headed by Wang $[106,107]$ performed two in vivo studies on human patients using PA imaging. Research group of Toi $[39,47,108,109]$ reported four in vivo studies during 2014-2017 on human patients using PA imaging during 2014-2017 and in 2015, the research group of Li [110] performed an in vivo study using functional PA imaging system for breast cancer detection.

Details of these studies performed by each research group are summarized below.

In a pilot clinical study conducted with the PA imaging system involving 27 patients, Ermilov et al. [66] successfully visualized 18 out of 20 malignant lesions suspected from the X-ray and the US images. Their findings were confirmed by the biopsy procedure, performed after the PA image acquisition. Zalev et al. [111] developed Imagio ${ }^{\mathrm{TM}}$ breast imaging system with a specialized duplex handheld probe by fusing a functional PA imaging with a gray-scale ultrasound. This system was tested on 74 breast masses and found that this system could provide better specificity and equal sensitivity as compared to conventional US imaging. Another pilot study was conducted by the same group involving the first 100 subjects from a multi-center pivotal study of Imagio ${ }^{\mathrm{TM}}$ system. The results of this study indicated that the number of all negative biopsies could be potentially reduced by $21.4 \%$. Neuschler et al. [37,38] performed a multi-center pivotal study during 2012-2015 involving 2105 women with 2191 breast masses using their dual mode PA-US imaging system (IMAGIO). From the 2191 masses, 210 masses were excluded due to technical failures/incomplete imaging, 78 masses were excluded due to protocol deviations, 43 masses were excluded due to high-risk histologic results along with 103 masses were excluded as they were utilized as training population. Finally, they have included only 1690 women with 1757 breast masses (benign cases: 1079 and malignant cases: 678) in their study analysis. From the results of their study, they claimed that the diagnostic specificity of the dual mode PA-US imaging system was improved $14.9 \%$ over the internal US imaging system alone. The study results support the utility of dual mode PA-US imaging system as a potential device for improving diagnostic performance of breast mass assessment. The dual mode PA US imaging technology can potentially improve specificity in differentiating between malignant and benign breast masses, which can reduce the number of benign breast mass biopsies as well as false-positive examinations. Neuschler et al. [112] performed a multicenter in vivo study with their dual mode PA-US imaging system on 94 breast masses. They found that the dual mode system showed $7.9 \%$ improvement in specificity compared to their US imaging system, whereas the sensitivities of both PA-US, as well as only the US system, were $97.1 \%$. Menezes et al. [104,105] performed a multicenter study during 2015-2016 using a dual mode PA-US imaging system on 215 breast masses which, prior to dual mode imaging, were assigned to specific BI-RADS categories based on the US imaging alone. 
They reported that 60 benign masses were correctly downgraded to a lower BI-RADS category using their dual mode PA-US imaging system. Menezes et al. [113] performed a dual-mode PA-US imaging in addition to internal gray-scale US imaging on 67 malignant breast masses. They used PA-US features to differentiate between breast cancer molecular subtypes. Dogan et al. [114] performed a detailed analysis on dual-mode PA US images of 532 IBC lesions of 519 patients from the PIONEER study. They correlated PA-US features with breast molecular subtypes.

In a small preclinical study, Manohar et al. [103] evaluated the performance of their Twente PAM on six patients at $1064 \mathrm{~nm}$. Out of the results presented in their report, one result indicated malignancy in the breast, which was not indicated by X-ray mammography and US imaging. Using the same system, Jose et al. [67] successfully located the tumors in the in vivo PA images of two patients. Piras et al. [115] performed in vivo study on three patients, two of them suffered from IDC, and one had a benign cyst. Their results showed that they successfully detected malignancies in the two cases with IDC, while the PA images of the patient with cyst did not produce any significantly strong PA signals corresponding to the benign pathology. In vivo PA imaging was conducted by Heijblom et al. [116] with Twente PAM for a patient with IDC where the malignant lesion was successfully located and visualized. In another in vivo study, performed by the same group [117] on ten patients with breast malignancy and two patients with a cyst, the results showed that the PA contrast generated by malignant pathology exceeded the corresponding X-ray contrast, whereas the two cases of cysts did not produce any significantly strong PA signals corresponding to benign pathology. In another study [36] on four patients with cysts, the results showed that appearances of cysts in the PA images acquired at a single wavelength were similar to that of malignancies. Heijblom et al. [25] used Twente PAM for the first time to relate tumor vascularization with the PA appearances of malignancies. From the study on a small patient population, they found that there were three specific types of PA lesion appearances-'mass', 'non-mass', and 'ring'. According to the researchers in these studies [25,118], 'mass' is a 3D lesion within the breast. It appears as a narrow region with high intensity. This region can be spatially homogenous or heterogeneous as well as of regular (round, oval, or lobulated) or irregular shape with vascularity spread over the entire lesion. 'Non-mass' appearance consists of a scattered region with multiple moderate to high-intensity foci, completely different in appearance from that of the surrounding healthy tissue. Vascularity was scattered over the entire lesion. 'Ring' appearance points to a high intensity region surrounding either partially or completely a region of low intensity. Vascularity was observed throughout the lesion while it was more pronounced at the border. Further, they [25] found that there was an excellent correspondence in lesion location identified by both PA and MRI and a reasonably good correlation in lesion shape and appearance. They also found that the lesion shape and appearance in PA images were in good correlation with standard histopathology. In their recent in vivo study on 33 breast malignancies with Twente PAM, Heijblom et al. [35] found that 32 malignancies appeared with high imaging contrast and was independent of radiographic breast density. Among these lesions, four representative cases of which two patients with IDC, one patient with mucinous carcinoma (MC), and 1 patient with ILC whose $X$-ray mammograms, PA images overlaid on X-ray mammograms and the PA volumes in the region of lesion interest are shown in the Figure 2. The lesions in PA volumes were perfectly localized with X-ray mammograms. These lesions appeared with high contrast in PA images and the lesions located at depths more than $20 \mathrm{~mm}$ were visualized on PA images with high contrast. 


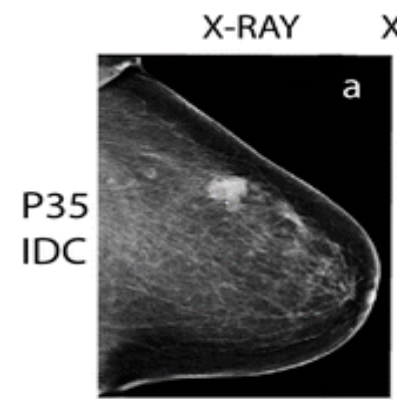

X-RAY+PHOTOACOUSTIC

PHOTOACOUSTIC 3D

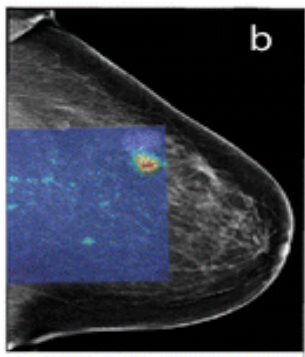

b
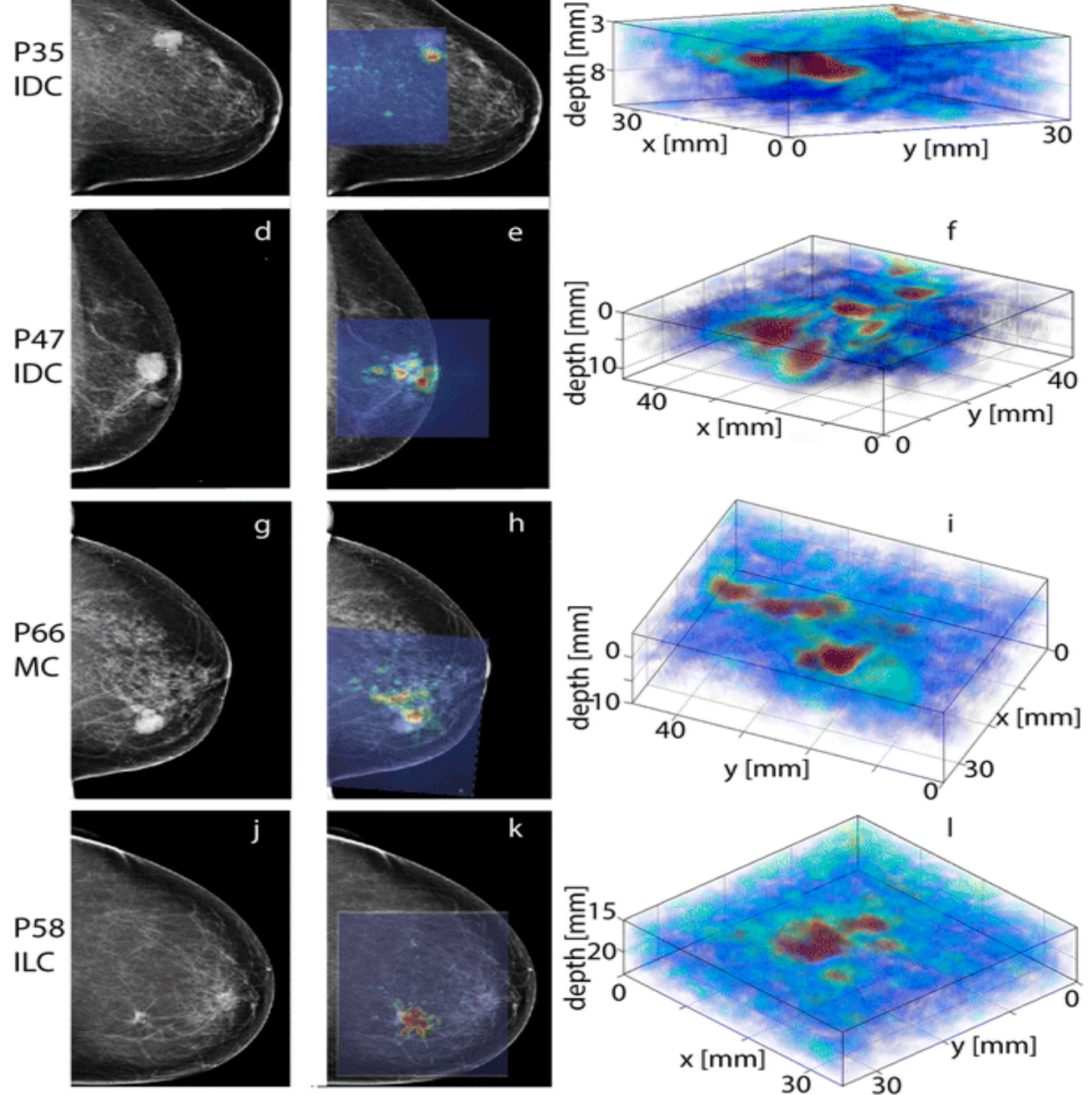

Figure 2. Comparison of PA imaging with X-ray mammograms. (Left): cranio-caudal (CC) X-ray mammogram; middle: PA images were overlaid on CC X-ray mammograms to show lesions in both modalities; (Right): detailed 3D representation of the lesion of interest. (a-c): Case 1, a 79-year-old patient with IDC, (d-f): Case 2, a 79-year-old patient with IDC, (g-i): Case 3, an 83-year-old patent with MC, and (j-1): Case 4, a 65-year-old patient with ILC. PXX indicates patient identifier used in this study. Reproduced from Heijblom et al. [35], which is distributed under the terms of the Creative Commons Attribution-Non Commercial 4.0 International License (http://creativecommons.org/licenses/by-nc/4.0/).

Kruger et al. [73] developed a 3D PA imaging system at $756 \mathrm{~nm}$ using a spherical detector aperture with 512 detectors with rectilinear scanning. They claimed that the system parameters of this 3D breast imaging system were sufficient enough to accommodate up to $90 \%$ of the breast volumes in the United States.

Garcia-Uribe et al. [107] developed a dual-modality PAT-US Imaging system at $650 \mathrm{~nm}$ and $1064 \mathrm{~nm}$ and tested its performance on sixteen patients. They found that clinically negative nodes in the axilla were observed in twelve patients, and clinically positive lymph nodes were observed in four patients. Their dual mode PA-US imaging system acted as a real-time imaging technology for SLN biopsy 
(SLNB) in locating the SLN first and then guiding the needle for lymph node sampling. As shown in Figure 3a,b, the respective US and PA images revealed the SLN and the needle used to insert the titanium marking clip. Figure $3 \mathrm{c}$ shows the co-registered PA-US image, which revealed the capability of this dual mode technology to locate the lymph nodes through anatomical features provided by US image as well as to verify the lymph node as sentinel through the PA image. The experimental results of this study showed that this system could detect SLNs and lymphatic vessels using methylene blue dye and also it could eliminate the need for invasive axillary staging procedures. Lin et al. [106] developed a 3D PA imaging system using a full ring 512-element ultrasonic transducer array, and conducted a pilot study on eight patients with this system. In one patient, they could detect a tumor, which was located at a depth of $\sim 32 \mathrm{~mm}$. The spatial resolution of this system was $255 \mu \mathrm{m}$ while the scanning time, which was approximately $15 \mathrm{~s}$, was within a single breath. This system acquired images of seven breast cancer patients with breast sizes ranging from B cup to DD cup, which could accommodate $99 \%$ of the U.S. population.
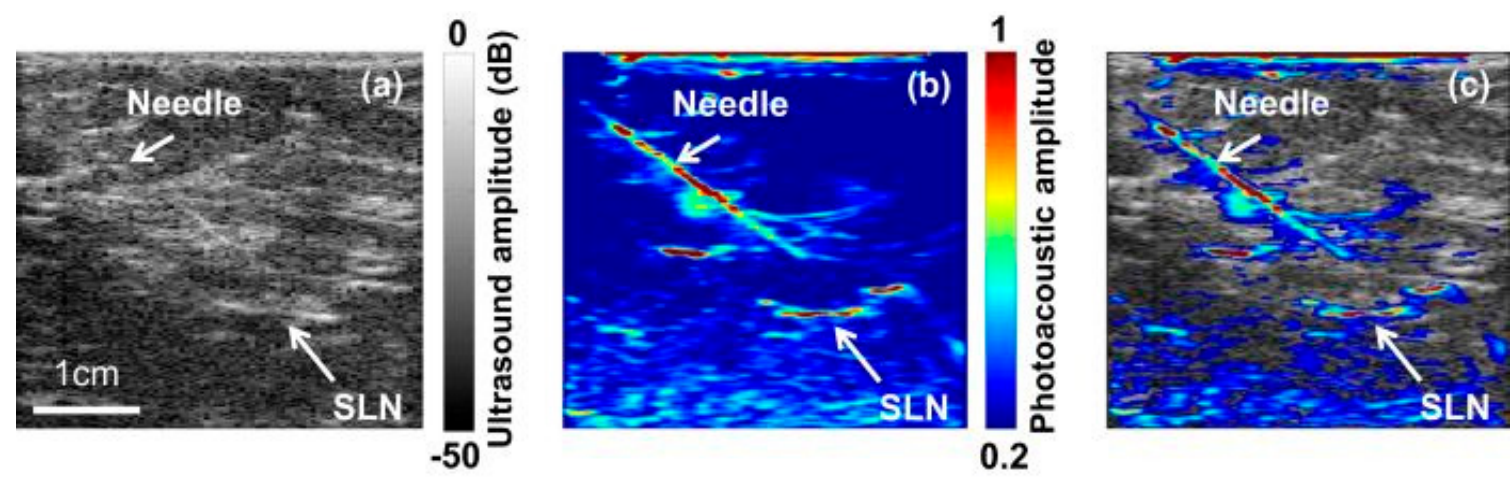

Figure 3. Comparison of PA, US and dual mode PA-US images of SNL showing the lymph node and needle. (a) US image, (b) PA image, and (c) co-registered PA-US image. Reproduced from Garcia-Uribe et al. [107], which is licensed under a Creative Commons Attribution 4.0 International License (http://creativecommons.org/licenses/by/4.0/).

Kitai et al. [108] evaluated the performance of their prototype machine (PAM-01) at $1064 \mathrm{~nm}$, $825 \mathrm{~nm}, 797 \mathrm{~nm}$, and $756 \mathrm{~nm}$ on 27 breast cancer lesions. From the measurements, they found that this system could give images of tumor vasculature and oxygenation, which could not be obtained either with X-ray mammography or US imaging. They also found that the PAM tumor images were comparable to that of MRI at relevant depths. Using the same prototype machine (PAM-01), Fakhrejahani et al. [109] successfully visualized 29 out of 39 lesions. They claimed that the vascular and oxygenation data obtained by this system represent a new, non-invasive imaging method that could potentially provide functional features of breast tumors. Asao et al. [47] developed a second generation prototype PAM (PAM-02) at $756 \mathrm{~nm}$ and $797 \mathrm{~nm}$ to simultaneously acquire PA and US images. They found that, unlike PAM-01, PAM-02 exhibited better PA image quality and improved spatial resolution from $2 \mathrm{~mm}$ to $1 \mathrm{~mm}$. Toi et al. [39] developed a PA imaging system (PAM-03) at $755 \mathrm{~nm}$ and $795 \mathrm{~nm}$ with a hemispherical detector array and tested its performance on 22 malignant cases. High-resolution 3D images obtained with this system showed finer vasculature. They adopted a technique in which the PA image was fused with the deformed MRI, and this fused image enabled precise visualization of tumor location. A comparison of PA and MR images of a healthy breast is shown in Figure 4. As shown in the fused PA-MR image (Figure 4c), the blood-vessel structures and morphological characteristics of the PA images were more detailed than MRI. 'More detailed' here refers to finer vasculature, more detailed blood vessel branching structures, and more detailed morphological vessel characteristics. 

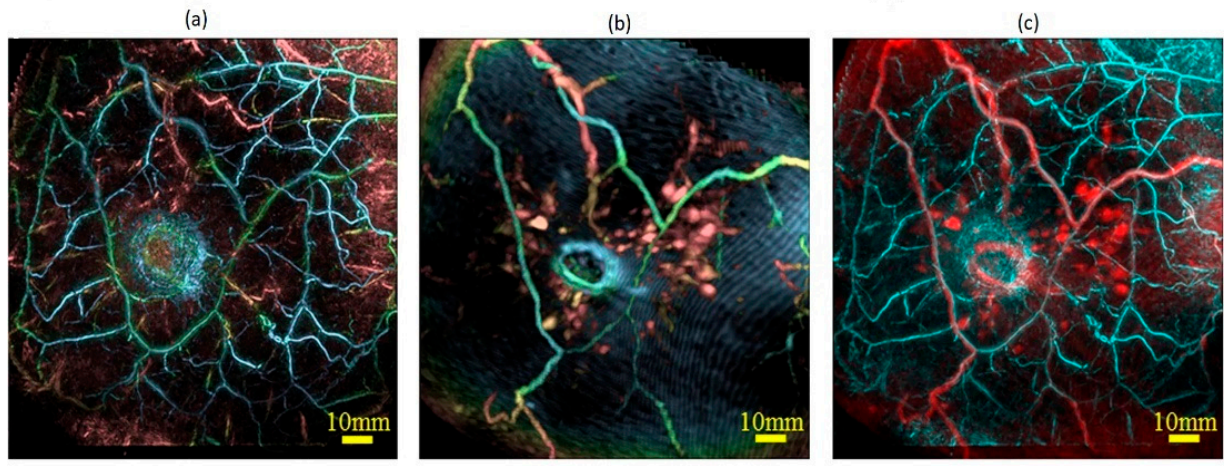

(d)

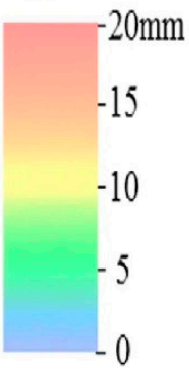

Figure 4. Comparison of PA and MR images of a healthy breast (a) PA image, (b) MR image, and (c) Fused PA-MR image with PA (cyan) and MR (red). Signals are colored according to the depth using the color chart shown in (d). Reproduced from Toi et al. [39], which is licensed under a Creative Commons Attribution 4.0 International License (http://creativecommons.org/licenses/by/4.0/).

Li et al. [110] evaluated the feasibility of functional PAT at $733 \mathrm{~nm}, 775 \mathrm{~nm}$, and $808 \mathrm{~nm}$ for high-resolution detection and characterization of breast cancer on six lesions. All the six breast lesions were successfully detected by this system and the results were consistent with that of MRI reports. Out of the six, five cancer cases were consistent with that of final pathology findings.

\section{Discussion}

Several research groups have been working on PA imaging for breast cancer for the last two decades, towards translation of PA imaging for breast cancer detection from the laboratory environment to the clinical domain. Table 5 summarizes the configuration of the latest version of the PA imaging systems used by different research groups or details of systems used by the research group for a major in vivo study. It also summarizes the corresponding performance details in terms of resolution, penetration depth, and field-of-view. 
Table 5. Comparative analysis of system configuration of various photoacoustic imaging systems used by different research groups.

\begin{tabular}{|c|c|c|c|c|c|c|c|c|c|}
\hline Research Group & $\begin{array}{c}\text { Optical } \\
\text { Wavelength(s) } \\
(\mathrm{nm})\end{array}$ & Detector & Reconstruction & Resolution & $\begin{array}{l}\text { Penetration } \\
\text { Depth }\end{array}$ & Field-of-View & $\mathbf{N}$ & Study Type & $\begin{array}{l}\text { Clinical } \\
\text { Study }\end{array}$ \\
\hline $\begin{array}{l}\text { S. Manohar Biomedical } \\
\text { Photonic Imaging Group } \\
\text { Twente PAM }[35,36]\end{array}$ & 1064 & $\begin{array}{l}\text { Planar, } 590 \text { elements, } \\
1 \mathrm{MHz}, 130 \% \\
\text { bandwidth }\end{array}$ & $\begin{array}{c}\text { Acoustic } \\
\text { back-projection } \\
\text { algorithm }\end{array}$ & $\begin{array}{c}3 \mathrm{~mm} \text { (axial and } \\
\text { lateral) }\end{array}$ & $25-30 \mathrm{~mm}$ & $90 \times 80 \mathrm{~mm}^{2}$ & 31 & In vivo & Yes \\
\hline $\begin{array}{c}\text { Kruger OptoSonics, Inc., } \\
\text { 3D PAT [40] }\end{array}$ & 800 & $\begin{array}{l}\text { Hemispherical, } \\
128 \text { elements, } 5 \mathrm{MHz}\end{array}$ & $\begin{array}{c}\text { Filtered } \\
\text { back-projection } \\
\text { algorithm }\end{array}$ & $\sim 250 \mu \mathrm{m}$ (spatial) & $40 \mathrm{~mm}$ & $64 \times 64 \times 50 \mathrm{~mm}^{3}$ & 01 & In vivo & No \\
\hline $\begin{array}{c}\text { Kruger OptoSonics, Inc., } \\
\text { 3D PAM [73] }\end{array}$ & 756 & $\begin{array}{l}\text { Spherical aperture, } \\
512 \text { elements, } 2 \mathrm{MHz} \\
70 \% \text { bandwidth }\end{array}$ & $\begin{array}{c}\text { Filtered } \\
\text { back-projection } \\
\text { algorithm }\end{array}$ & $0.42 \mathrm{~mm}$ (spatial) & $53 \mathrm{~mm}$ & $\begin{array}{l}1335 \mathrm{~mL} \text { (breast } \\
\text { size) }\end{array}$ & 04 & In vivo & No \\
\hline $\begin{array}{l}\text { Oraevsky Tomowave } \\
\text { Laboratories, Inc. } \\
\text { LOUIS-3D [119,120] }\end{array}$ & 1064 & $\begin{array}{c}\text { Arc, } 96 \text { elements, } \\
\text { bandwidth } 50 \mathrm{KHz} \text { to } \\
6 \mathrm{MHz}\end{array}$ & & $\sim 0.28 \mathrm{~mm}$ & & & 100 & In vivo & $\begin{array}{l}\text { Pilot } \\
\text { clinical } \\
\text { study }\end{array}$ \\
\hline $\begin{array}{l}\text { L.V. Wang Optical Imaging } \\
\text { Laboratory Tri-modality } \\
\text { TAT/PAT/US [70] }\end{array}$ & 650 & $\begin{array}{c}\text { Ultrasound phased } \\
\text { array, } 80 \text { elements, } \\
\text { bandwidth } 1 \mathrm{MHz} \text { to } \\
5 \mathrm{MHz}\end{array}$ & $\begin{array}{l}\text { Delay and } \\
\text { Sum/Fourier beam- } \\
\text { forming algorithm }\end{array}$ & $\begin{array}{c}640 \mu \mathrm{m} \text { (axial), } \\
720 \mu \mathrm{m} \text { (lateral), } \\
\text { and } 3.5 \mathrm{~mm} \\
\text { (elevational) }\end{array}$ & $66 \mathrm{~mm}$ & NA & & $\begin{array}{l}\text { Animal } \\
\text { (Chicken } \\
\text { Breast tissue) }\end{array}$ & No \\
\hline $\begin{array}{l}\text { L.V. Wang Caltech Optical } \\
\text { Imaging Laboratory [106] }\end{array}$ & 1064 & $\begin{array}{l}\text { Full-ring, } 512 \text { elements, } \\
2.25 \mathrm{MHz}, 95 \% \\
\text { bandwidth }\end{array}$ & $\begin{array}{l}\text { 3D back-projection } \\
\text { algorithm }\end{array}$ & $255 \mu \mathrm{m}$ spatial & $32 \mathrm{~mm}$ & $\begin{array}{c}\text { Accommodate } \\
\text { breast sizes ranging } \\
\text { from B cup to DD } \\
\text { cup }\end{array}$ & 08 & In vivo & Pilot study \\
\hline $\begin{array}{c}\text { Toi Kyoto University, Japan } \\
\text { PAM-03 [39] }\end{array}$ & 755,795 & $\begin{array}{l}\text { Hemispherical, } \\
512 \text { elements, } 2 \mathrm{MHz} \\
70 \% \text { bandwidth }\end{array}$ & $\begin{array}{l}\text { Universal } \\
\text { back-projection } \\
\text { algorithm }\end{array}$ & & $27 \mathrm{~mm}$ & & 30 & In vivo & Yes \\
\hline $\begin{array}{c}\text { IMAGIO }^{\mathrm{TM}} \text { Seno } \\
\text { Medical Instruments Inc. } \\
\text { IMAGIO }^{\mathrm{TM}} \\
\text { Seno Medical } \\
\text { Instruments Inc. }[37,38]^{\#}\end{array}$ & $\begin{array}{l}1064 \text { (Nd:YAG } \\
\text { laser), } 757 \\
\text { (Alexandrite } \\
\text { laser) }\end{array}$ & $\begin{array}{c}\text { Linear, } 128 \text { elements, } \\
\text { bandwidth } 4 \mathrm{MHz} \text { to } \\
16 \mathrm{MHz}\end{array}$ & $\begin{array}{l}\text { Back-projection of } \\
\text { filtered and } \\
\text { weighted } \\
\text { optoacoustic signals }\end{array}$ & $\begin{array}{l}\text { Nd: YAG laser: } \\
0.42 \mathrm{~mm} \text { (axial) } 0.73 \\
\text { (lateral) Alexandrite } \\
\text { laser: } 0.47 \mathrm{~mm} \\
\text { (Axial) } 0.81 \mathrm{~mm} \\
\text { (lateral) }\end{array}$ & & & 2105 & In vivo & Yes \\
\hline
\end{tabular}

\# These systems have handheld probe configuration, N-patient population, NA—not applicable. 


\subsection{Comparison of PA Imaging with Other Imaging Modalities}

To evaluate the potential of the PA imaging to detect breast cancer, it is essential to compare the performance of PA imaging with that of the existing imaging modalities. In this section, the performance of PA imaging for breast cancer detection is compared with that of X-ray, US, and MR imaging, using the results of the in vivo studies involving PA imaging.

\subsubsection{PA Imaging Versus X-ray Mammography and US Imaging}

The most commonly used imaging modalities for breast cancer screening or detection are X-ray mammography and US imaging. As mentioned earlier, the research groups of Heijblom et. al. [35,117], Zalev et al. [111], Neuschler et al. [37], Lin et al. [106], and Kitai et al. [108] compared the results of PA imaging with that of X-ray as well as US imaging. Heijblom et al. [117] showed that the PA contrast generated by malignant pathology exceeded the corresponding X-ray contrast. They identified [35] 3 cases among a total of 32 cases, for which the lesions could not be detected using X-ray mammogram while the same lesions appeared with high contrast in the corresponding PA images. They observed that in the case of X-ray mammogram, the contrast of lesions in high-density breasts was lower than those in the low-density breasts while they could not find any significant difference in the average contrast of lesion PA images between the high-density and low-density breasts. According to their results, the deviation of the average size of the lesion detected in PA mammography with respect to the corresponding histopathology was $28 \%$ whereas, in X-ray mammography, it was $34 \%$. In a pilot study involving eight patients, with a 3D PA imaging system, Lin et al. [106] detected tumors which were not clearly distinguishable with $\mathrm{X}$-ray mammograms for two patients. From these studies, it was observed that PA imaging could be effectively used to visualize the tumors in radiographically dense breasts and occult lesions, which were not clearly identified with X-ray mammograms. For breast cancer detection using PA imaging, the contrast of the tumor is due to the difference in concentration of different forms of hemoglobin (primarily deoxygenated hemoglobin $(\mathrm{Hb})$ and oxygenated hemoglobin $\left(\mathrm{HbO}_{2}\right)$ ) between tumor and background tissue, which is independent of the mammographically-estimated breast density [117]. The malignant tumors are having higher total hemoglobin concentration and lower oxygen saturation as compared to background breast tissue. PA imaging provides tumor vasculature and oxygenation, which cannot be obtained by X-ray mammogram [108].

As far as US imaging is concerned, Heijblom et al. [35] found that out of the 31 patients, for one patient the malignant lesion could not be detected using US image whereas it appeared with high contrast in the corresponding PA image. The average size deviation of the lesion detected using PA imaging with respect to the corresponding histopathology was $28 \%$, whereas, in the case of US imaging, it was $18 \%$. Kitai et al. [108] acquired in vivo images of 27 breast cancer lesions and concluded that information regarding the tumor vasculature and oxygenation could be obtained from PA images while US or X-ray imaging could not provide similar information. Zalev et al. [111] found that their Imagio $^{\mathrm{TM}}$ breast imaging system provides better specificity and equal sensitivity as compared to conventional US imaging. Neuschler et al. [37] performed a multi-center pivotal study with their dual mode PA-US imaging system, and from the results of their study, they claimed that the diagnostic specificity of the fused PA-US imaging system was improved $14.9 \%$ over the internal US imaging system alone. US is one of the most common imaging modalities which has been widely used by radiologists for decades, while PA imaging is an emerging imaging modality. Due to the high cost of the nanosecond duration pulse laser, the cost of PA imaging system is higher than the US imaging system. However, as both PA imaging and US imaging share the common detector technology, almost all the PA imaging systems can be used as dual mode PA US imaging systems to exploit the advantages of both PA and US imaging. To develop a PA imaging system, only the nanosecond duration pulsed laser is to be added with an existing US imaging system and since US imaging has a widespread use in present day healthcare, in exchange of the price of the nanosecond pulsed laser, a dual mode PA US imaging system can be easily developed. 


\subsubsection{PA Imaging Versus MRI}

When X-ray mammography produces conflicting inference with that of the US image, MR imaging was performed before referring the patient for biopsy procedure [10]. MRI provides better sensitivity than X-ray mammogram or US imaging for breast cancer detection [15]. Heijblom et al. [25], Kitai et al. [108], Toi et al. [39], and Li et al. [110] compared the performance of the PA imaging with that of the MR images acquired of the same patients. For a total of 11 patients, Heijblom et al. [25] observed the excellent correspondence between PA images and MR images in terms of lesion localization, lesion shape, and appearance. They observed [35] that the average size deviation of the lesion detected in PA imaging with respect to the lesions detected in histopathology was $28 \%$ whereas, in MRI, it was $65 \%$. Kitai et al. [108] acquired in vivo PA images of 27 breast cancer lesions and concluded that PA images of the tumors were comparable to the corresponding MR images at relevant depths. Toi et al. [39] acquired high-resolution in vivo 3D PA images of breast cancer lesions, and they observed that the blood vessel structures and morphological characteristics of these images were more detailed than those observed in the corresponding MR images. These study results suggest that the contrast was better, as the small blood vessels and their branching structures were more clearly visible in PA images than MR images. Li et al. [110] detected six breast lesions using functional PA imaging and matched the results with that of the corresponding MR images. A retrospective study performed by Raikhlin et al. [121] on 650 high-risk women undergone $806 \mathrm{MRI}$ and X-ray mammography screening rounds reported that breast MRI was more sensitive than X-ray mammograms (92.3\% vs. $30.8 \%)$ while the specificity provided by breast MRI was less than the X-ray mammograms ( $85.9 \%$ vs. $96.8 \%$ ). High sensitivity of breast MRI results in more false positive findings than X-ray mammograms. A study performed on largest number of patients [37] reported that the dual mode PA-US imaging has the potential in reducing the number of false positive examinations as compared to US alone.

\subsubsection{PA Imaging Versus Histology}

Heijblom et al. [35], Li et al. [110], and Menezes et al. [113] validated their findings from the in vivo PA images with the corresponding histopathology images. Heijblom et al. [35] found that the average size deviation of the lesions detected in PA imaging with respect to the corresponding lesions detected in histopathology was $28 \%$. For six cases out of 29, they [25] compared PA images with the corresponding histopathology images. They observed a good correlation between PA and the corresponding histology images in terms of lesion shape and size. Out of the six cases detected by Li et al. [110] using in vivo PA imaging, for five cases the results were consistent with that of the final pathology. From these studies, it was observed that in addition to lesion size, lesion shape and appearance of PA images were also correlated with histology. Menezes et al. [113] reported typical PA-US and histopathological differences between triple-negative breast cancers (TNBCs) and luminal-A (LUMAs) molecular subtypes. In case of TNBCs, they observed rich internal findings and relative lack of external peripheral zone findings in PA-US feature scores. LUMAs showed more prominent external peripheral zone radiating vessels but reduced PA-US internal feature scores. Among PA-US features, they found significant correlations between PA-US internal feature scores and the secondary histopathological indicators such as continuous number of mitoses, estrogen receptor (ER) status and Ki-67 percentages.

\subsection{Patient Population in Clinical Studies}

Translation of an imaging system from research level to clinical practice requires that the performance of the imaging system should be evaluated with a large number of clinical studies involving large patient population. In this subsection, the patient population involved in the clinical studies conducted by various groups was listed. Heijblom et al. [35] included 31 patients in their recent clinical study using Twente PAM. A pilot clinical study involving 16 patients was conducted by Garcia-Uribe et al. [107] using their dual modality PA and US imaging system. Kruger et al. [73] 
performed an in vivo study involving four patients with their 3D PA breast imaging system. Toi et al. [39] tested the performance of their PA imaging system (PAM-03) on 22 malignant cases and in their previous clinical study [108], they evaluated the performance of their prototype machine (PAM-01) on 27 breast cancer lesions. Zalev et al. [111] tested their Imagio ${ }^{\mathrm{TM}}$ breast imaging system on 74 breast masses. Another pilot study was conducted by the same group involving the first 100 subjects from a multi-center pivotal study of Imagio ${ }^{\mathrm{TM}}$ system. Except for the multi-center pivotal study involving 2105 subjects conducted by Neuschler et al. [37], the patient population involved in the studies of other research groups is not sufficient. Except for the PIONEER study with 2105 patients, the patient population in all other studies was very small. This kind of studies with a small population may not be sufficient to confirm the potential of PA imaging for breast cancer diagnosis as well as screening. Large numbers of clinical studies involving large patient population are expected to be done in the near future to bring these PA imaging systems into regular clinical practice.

\subsection{Comparison of PA Imaging System Configurations}

Table 5 shows that as far as the resolution is concerned, 3D PA imaging system developed by Kruger et al. [40] provided the best spatial resolution which is approximately equal to $250 \mu \mathrm{m}$. 3D PA imaging system developed by Lin et al. [106] provided a comparable spatial resolution of $255 \mu \mathrm{m}$ to that of the PA imaging system developed by Kruger et al. [40]. As far as the depth of penetration is concerned, the PA imaging system developed by Ke et al. [70] which was evaluated using an ex-vivo study on chicken breast tissue, provided maximum penetration depth of $66 \mathrm{~mm}$. As far as flexibility and versatility are concerned, we regard 3D PA imaging systems developed by Kruger et al. [73] and Lin et al. [106] to be the best, as they could accommodate a wide variety of patient population and provide excellent image resolution.

\subsection{Spectroscopic Imaging}

In their in vivo study, Kitai et al. [108] acquired PA images at $756 \mathrm{~nm}$ and $797 \mathrm{~nm}$ and using these PA images they evaluated the oxygen saturation of hemoglobin $\left(\mathrm{SO}_{2}\right)$ and total hemoglobin concentration ( $\mathrm{HbT})$ of the lesions. Asao et al. [47] developed a dual-mode PA and US imaging system which acquired PA images at $756 \mathrm{~nm}$ and $797 \mathrm{~nm}$. Toi et al. [39] acquired in vivo PA images of 22 malignant cases at $756 \mathrm{~nm}$ and $797 \mathrm{~nm}$. Li et al. [110] evaluated the feasibility of functional PAT at $733 \mathrm{~nm}, 775 \mathrm{~nm}$, and $808 \mathrm{~nm}$ for high-resolution detection and characterization of breast cancer on six lesions. Becker et al. [122] performed a clinical study on 6 cases of healthy breasts, five cases of IBCs and two cases of DCIS with their handheld dual mode PA-US imaging system and acquired PA images at five different wavelengths $700 \mathrm{~nm}, 730 \mathrm{~nm}, 760 \mathrm{~nm}, 800 \mathrm{~nm}$, and $850 \mathrm{~nm}$. Using multiwavelength PA data, they estimated the concentration of deoxygenated hemoglobin $(\mathrm{Hb})$, oxygenated hemoglobin $\left(\mathrm{HbO}_{2}\right), \mathrm{HbT}$, and $\mathrm{SO}_{2}$. They observed that for IBC patients, the concentration of $\mathrm{Hb}, \mathrm{HbO}_{2}, \mathrm{HbT}$ corresponding to diseased tissue increased compared to healthy breast tissue while, for DCIS cases, these parameters corresponding to diseased tissue varied slightly relative to healthy patients. Diot et al. [123] performed a pilot clinical study on three cases of healthy breasts, two cases of IBCs and eight malignant cases of non-specific breast cancers with their PAT system and acquired PA images at 28 different wavelengths. Using multiwavelength PA data, they estimated the concentration of $\mathrm{Hb}, \mathrm{HbO}_{2}, \mathrm{HbT}$, lipid, and water. For a wide range of tumor sizes, they found that $\mathrm{HbT}$ concentrations at the tumor periphery are higher than that of $\mathrm{HbT}$ concentrations within tumors. Abeyakoon et al. [124] performed a spectroscopic PA imaging at three wavelengths $700 \mathrm{~nm}, 800 \mathrm{~nm}$, and $850 \mathrm{~nm}$ using their integrated PA-US imaging system to detect physiological changes in the breast during the menstrual cycle. They included 22 pre-menopausal and eight post-menopausal volunteers in their study and found that PA-US intensity values in the secretory phase were significantly higher than that of the proliferative phase. 


\subsection{Breast Cancer Treatment Monitoring}

From the literature it was found that PA imaging can be used to monitor the efficacy of anti-cancer treatments, such as chemotherapy or molecular targeting therapies, through the changes in the PA images of tumor-related blood vessels. Intratumoral blood flow visualization and oxygen status of hemoglobin in the blood vessels through PA imaging enables a detailed understanding of tumor microenvironment during and after the treatment. Li et al. [125] performed a multiwavelength PA imaging study on a patient (46-year-old-female) with a high-grade DCIS and IBC before neoadjuvant chemotherapy. From the PA images obtained before the treatment, after each month during the treatment for first three consecutive months and after the treatment before surgery, they observed a gradual decrease in the lesion area (from $217.8 \mathrm{~mm}^{2}$ to $39.9 \mathrm{~mm}^{2}$ ) as well as contrast due to total hemoglobin (from 2.6 to 1.7) and oxygen saturation (from 1.3 to 1.1) in the lesion. They reported that their findings with PA images were also compatible with MRI and US diagnosis reports. Toi et al. [39] demonstrated that the tumor associated blood vessels in a patient with IBC became visible in PA images after chemotherapy. Hysi et al. [126] performed a PA imaging study at 750/850 $\mathrm{nm}$ on EMT-6 breast cancer tumor injected into mice to monitor the response of a thermosensitive liposome treatment. They observed the response of the treatment though PA images obtained at different time points $30 \mathrm{~min}$ before and after treatment up to seven days after treatment. They reported that the liposome encapsulated doxorubicin (HaT-DOX) treatment responders at $2 \mathrm{~h}$ after treatment have shown $22 \%$ decrease in oxygen saturation (indicating treatment-induced vascular destruction) and a $45 \%$ and $73 \%$ decrease in the slope of normalized PA frequency spectra (indicates treatment induced morphological changes of blood vessels) at $750 \mathrm{~nm}$ and $850 \mathrm{~nm}$, respectively.

\subsection{Questions Raised by Manohar's Research Group and Answers}

For the successful translation of a new imaging modality from the laboratory environment to the clinical environment, researchers have to provide answers, supported by experimental evidence, to certain questions related to the role and utility of the imaging technology for detection and diagnosis of particular diseases. Heijblom et al. [127] identified some important questions to evaluate the utility of using PA technology in the clinical environment for imaging of breast cancer. In this subsection, we summarized the experimental evidence, obtained so far by the different groups to answer the questions raised by Heijblom et al. [127].

Question 1: What are the PA appearances of different varieties of breast cancer such as IDC, ILC, DCIS, and fibroadenoma?

An in vivo study reported that the centripetal blood vessel structure was observed in the PA images of IBC cases, whereas intratumoral spotty signals were observed in the PA images DCIS cases. In another in vivo study, appearance of IDC lesions in the PA images were divided into three categories, namely mass, non-mass, and ring structures. Details of these two studies were described below.

In their in vivo study, Toi et al. [39] selected five markers related to the vasculature in the detected lesion and on the basis of the presence of these five markers, compared the PA images of patients suffering from IBC with the PA images of DCIS patients. According to their findings, there was a significant difference of centripetal vasculature between the PA images of IBC patients and that of DCIS patients. An example of MR, PA, and their fused images of a 40-year-old woman with IBC, shown in Figure $5 \mathrm{a}-\mathrm{d}$, demonstrates the centripetal vasculature. Centripetal vasculature refers to vasculature which tends to converge towards the center of the tumor from the normal breast tissue. In this, the blood vessels tend to become rapidly narrowing at the periphery of the tumor and they seem to be almost vanishing at the center of the tumor. They also observed, although there was no statistical significance, that PA images of IBC cases contained more intratumoral vasculature-like linear signals, while PA images of DCIS cases contained more intratumoral spotty signals. 
(a)

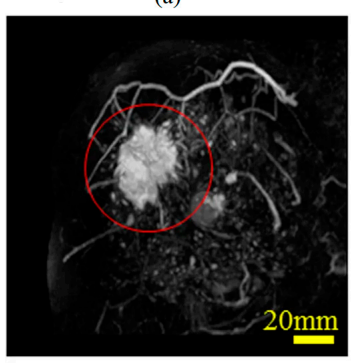

(e)

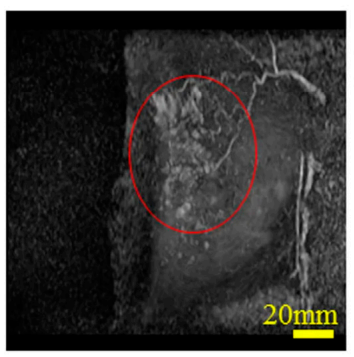

(b)

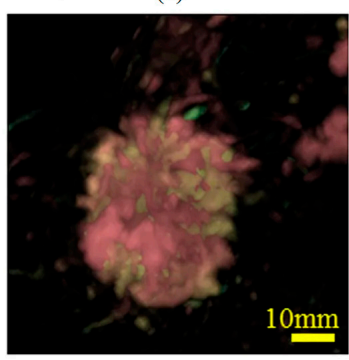

(f)

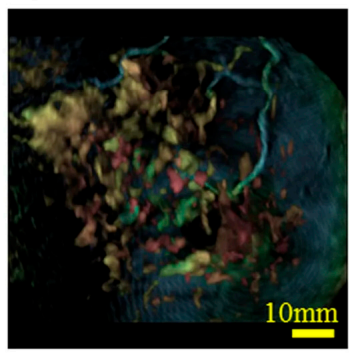

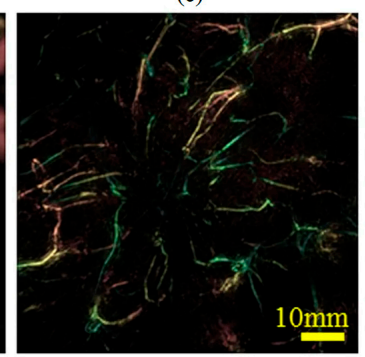

(g)

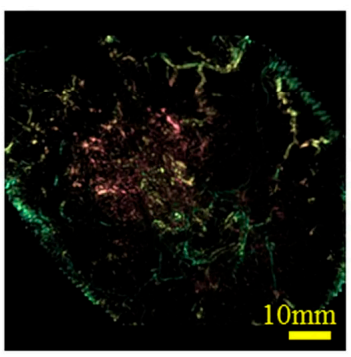

(d)

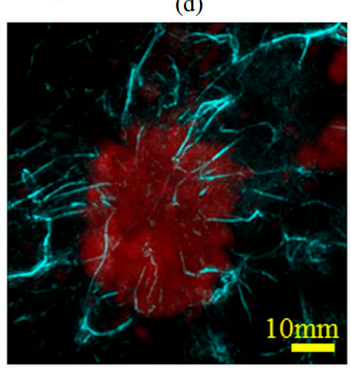

(h)

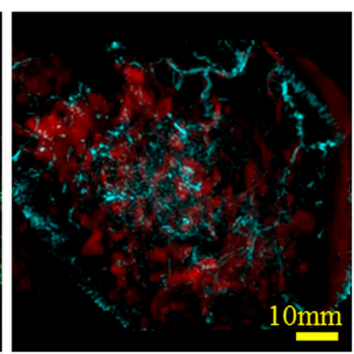

Figure 5. Example of MR, PA and their fusion images of two cases. Case 1 (a-d): A 40-year-old woman with IBC. Case 2 (e-h): A 46-year-old woman with DCIS in upper-outer area in right breast. $(\mathbf{a}, \mathbf{e})$ Original MR image, lesion is indicated by a red circle; $(\mathbf{b}, \mathbf{f})$ the enlarged MR images around the lesion after deforming into the shape to PA images; $(\mathbf{c}, \mathbf{g})$ and $(\mathbf{d}, \mathbf{h})$ are original PA images, and fusion images of PA (cyan) and MR (red), respectively; these figures are after eliminating the PA signals from subcutaneous blood vessels by a depth of $4 \mathrm{~mm}$. Reproduced from Toi et al. [39], which is licensed under a Creative Commons Attribution 4.0 International License (http://creativecommons.org/licenses/by/4.0/).

In the in vivo PA imaging study conducted with primary patients suffering from IDC, Heijblom et al. $[25,35]$ observed that appearances of the lesions in the corresponding PA images generally fall into three categories namely 'mass or confined', 'non-mass or scattered', and 'ring'.

Toi et al. [39], observed that the PA images of five patients with DCIS contained intratumoral spotty signals as shown in Figure 5e-h for a 46-year-old woman with DCIS, while the PA images of 17 patients with IBC contained centripetal blood vessel structure as shown in Figure $5 \mathrm{a}-\mathrm{d}$ for a 40 -year-old woman with IBC and intratumoral vasculature-like linear signals. Heijblom et al. $[25,35]$ reported that the PA images of breasts with IDC contained mass, non-mass, and ring-like structures. However, due to the small number of cases reported in these two studies, generalized comments on the specific PA markers corresponding to different types of breast cancer is not possible.

Question 2: What are the pathophysiological factors behind the PA signatures of the breast cancer and whether the PA signatures can be related to angiogenic or vasculature distribution? Can these PA signatures be used for breast cancer diagnosis?

Some studies have identified different patterns of vasculatures associated with different types of cancers and patients behind different PA signatures. However, the diagnostic capabilities of these PA signatures were not evaluated in these studies.

Heijblom et al. [25] compared the PA images of some of the breast cancer patients with the corresponding histopathology images. For the three cases with PA 'mass' appearance, they observed that the vasculature was spread throughout the lesion from the corresponding CD31 histopathology. They correlated the case of PA 'non-mass' appearance with vascular pattern most pronounced in non-cohesively organized vasculature fields. Non-cohesively organized vasculature fields are scattered or unconnected vasculature fields. For the case of PA 'ring' appearance, they observed the vasculature to be confined to the border. They also provided the physiological explanation for the few cases in which the PA lesion appearance do not fall within the above mentioned three major categories, or they 
contradict the corresponding MRI findings. As mentioned in the previous paragraph containing the evidence in support of Question 1, Toi et al. [39] attempted to analyze the different varieties of breast cancer by detecting five different PA markers related to lesion vasculature. For the above-mentioned studies, specific PA appearances for a limited number of cases were correlated with the corresponding physiology. However, these studies did not evaluate the diagnostic capabilities of those specific PA appearances/markers. Menezes et al. [113] performed a dual-mode PA-US imaging in addition to internal gray-scale US imaging on 67 malignant breast masses. They used PA-US features to differentiate between breast cancer molecular subtypes. They reported that among PA-US features, the sum of internal features was useful to differentiate between triple-negative breast cancer (TNBC) and HER2 enriched breast cancer subtypes. Internal vessels, the sum of all internal features, the sum of all internal and external features of PA-US images were useful to differentiate between Luminal A (LUMA) and Luminal B (LUMB) molecular subtypes. All internal features, the sum of all internal features, the sum of all external features, the sum of all internal and external features, and the ratio of internal and external features of PA-US images were useful to differentiate between LUMA and TNBC molecular subtypes. They also found that the same features could be useful to differentiate between LUMA and TNBC from other molecular subtypes. Dogan et al. [114] performed a detailed analysis on dual mode PA US images of 532 IBC lesions of 519 patients from the PIONEER study. They reported that the means of total external PA-US feature scores, i.e., boundary zone, peripheral zone vessels for luminal (A and B) breast cancers were higher, and total internal PA-US features scores, i.e., internal vessels, internal blush, and internal hemoglobin were lower than that of the triple-negative and HER2positive breast cancers.

Question 3: Whether it is possible to identify PA image markers for differentiating between contralateral breast and the healthy breast?

A small number of clinical studies show that there were significant differences among the PA images of the healthy breast and the contralateral breast.

In their in vivo study, Fakhrejahani et al. [109] observed that the saturated oxygen level of the affected breast masses was lower than the contralateral breasts and healthy breasts. Toi et al. [39] observed that the contralateral breasts are having lower PA signals than that of the affected breast. However, these clinical studies did not give any specific PA image marker to differentiate between the contralateral and healthy breast. Yamaga et al. [128] performed a three-dimensional PA imaging with a hemispherical detector array on 22 patients with unilateral breast cancer to identify a potential biomarker for breast cancer. They concluded that an increased average count of vessel branching points at a superficial depth below breast skin might indicate the presence of the primary breast cancer as compared with that of the contralateral unaffected breasts.

Question 4: How much beneficial PA imaging will be for screening, detection, and diagnosis of breast cancer. Whether PA imaging can be utilized for dense breast imaging and neoadjuvant chemotherapy monitoring?

From the results of clinical studies conducted so far by different research groups, it can be said that PA imaging can be utilized for the detection of breast cancer. However, there is no clear experimental evidence to support the utility of PA imaging in breast cancer screening. Very few clinical studies $[25,35,37,39]$ have been done so far, and the results of these studies indicate that PA imaging can potentially be used for breast cancer diagnosis. However, for gathering conclusive evidence in support of the capability of PA imaging for breast cancer diagnosis, a significant number of clinical studies with large population must be performed.

In the clinical study performed by Heijblom et al. [35] they observed that there was no noteworthy difference in the average PA contrast among the X-ray low-dense and high-dense breasts. Toi et al. [39] observed that, following chemotherapy, intramural blood flow was increased by which the blood vessels inside the tumor became visible. This shows that PA imaging may potentially be utilized for monitoring chemotherapy. 


\section{Conclusions}

This study indicates that over the last two decades, as far as breast cancer detection is concerned, PA imaging systems have been significantly improved by customizing US detector assembly as well as scanning configurations. However, there is a great need to perform a significant number of in vivo studies under the clinical environment with a large patient population belonging to different breast cancer types. Such studies enable the researchers to answer clinically relevant questions, like whether there is any unique PA signature corresponding to breast cancer in the early stage, and whether there are different PA signatures corresponding to different types of breast cancers, etc. Based on the experimental evidence obtained so far, it can be concluded that PA imaging can be used for detection of breast cancer. There is no clinical evidence to support the utility of PA imaging for breast cancer screening. However, as far as the breast cancer diagnosis is concerned, additional clinical studies are required to be performed to evaluate the diagnostic potential of photoacoustic imaging for identifying different types of breast cancer. In the future, the functional imaging capability of spectroscopic PA imaging needs to be exploited with more in vivo studies conducted at multiple wavelengths. To reduce the cost of the functional PA imaging system, the expensive multi-wavelength laser can be replaced with laser diodes with different wavelengths.

Author Contributions: Conceptualization: A.P.R. and S.S.; methodology: A.P.R. and N.B.; formal analysis: A.P.R. and S.S.; resources: A.P.R. and N.B.; writing —original draft preparation: A.P.R.; writing—review and editing: N.B. and S.S.; supervision: S.S. All authors have read and agreed to the published version of the manuscript.

Funding: This study has received funding by the Ministry of Electronics and Information Technology, Government of India, grant/order number-PhD-MLA/4(14)/2015-16, Dated: 03-09-2015.

Conflicts of Interest: The authors declare no conflict of interest.

\section{References}

1. Fitzmaurice, C.; Allen, C.; Barber, R.M.; Barregard, L.; Bhutta, Z.A.; Brenner,H.; Dicker, D.J; Chimed-Orchir, O.; Dandona, R.; Dandona, L. Global, regional, and national cancer incidence, mortality, years of life lost, years lived with disability, and disability-adjusted life-years for 32 cancer groups, 1990 to 2015: A systematic analysis for the global burden of disease study. JAMA Oncol. 2017, 3, 524-548. [PubMed]

2. American Cancer Society. Types of Breast Cancer. Available online: https://www.cancer.org/cancer/breastcancer/understanding-a-breast-cancer-diagnosis/types-of-breast-cancer.html (accessed on 17 February 2017).

3. American Cancer Society, Inc. Surveillance Research. Estimated Number* of New Cancer Cases and Deaths by Sex, US, 2017. Available online: https://www.cancer.org/content/dam/cancer-org/research/cancer-factsand-statistics/annual-cancer-facts-and-figures/2017/estimated-number-of-new-cancer-cases-and-deathsby-sex-us-2017.pdf (accessed on 17 February 2017).

4. American Cancer Society. Cancer Facts \& Figures 2018. Available online: https://www.cancer.org/content/ dam/cancer-org/research/cancer-facts-and-statistics/annual-cancer-facts-and-figures/2018/cancer-factsand-figures-2018.pdf (accessed on 26 September 2018).

5. American Cancer Society. Cancer Facts \& Figures 2019. Available online: https://www.cancer.org/content/ dam/cancer-org/research/cancer-facts-and-statistics/annual-cancer-facts-and-figures/2019/cancer-factsand-figures-2019.pdf (accessed on 15 January 2019).

6. Saslow, D.; Boetes, C.; Burke, W.; Harms, S.; Leach, M.O.; Lehman, C.D.; Morris, E.; Pisano, E.; Schnall, M.; Sener, S. American Cancer Society guidelines for breast screening with MRI as an adjunct to mammography. CA Cancer J. Clin. 2007, 57, 75-89. [CrossRef] [PubMed]

7. American Cancer Society. Breast Cancer Early Detection and Diagnosis. Available online: https://www.cancer.org/cancer/breast-cancer/screening-tests-and-early-detection/american-cancer-societyrecommendations-for-the-early-detection-of-breast-cancer.html\#written_by (accessed on 1 December 2017).

8. World Health Organization. Guide to Cancer Early Diagnosis; World Health Organization: Geneva, Switzerland, 2017.

9. Newton, E.; Lee, M. Breast Cancer Screening. Available online: https://emedicine.medscape.com/article/ 1945498-overview (accessed on 7 March 2019). 
10. Xia, W.; Steenbergen, W.; Manohar, S. Photoacoustic mammography: Prospects and promises. Breast Cancer 2014, 3, 387-390. [CrossRef]

11. Gøtzsche, P.C.; Nielsen, M. Screening for breast cancer with mammography. Cochrane Database Syst. Rev. 2009, 4, 1-73.

12. Köşüş, N.; Köşüş, A.; Duran, M.; Simavlı, S.; Turhan, N. Comparison of standard mammography with digital mammography and digital infrared thermal imaging for breast cancer screening. J. Turk. Ger. Gynecol. Assoc. 2010, 11, 152. [CrossRef]

13. Buist, D.S.; Porter, P.L.; Lehman, C.; Taplin, S.H.; White, E. Factors contributing to mammography failure in women aged 40-49 years. J. Natl. Cancer Inst. 2004, 96, 1432-1440. [CrossRef]

14. Berg, W.A.; Gutierrez, L.; NessAiver, M.S.; Carter, W.B.; Bhargavan, M.; Lewis, R.S.; Ioffe, O.B. Diagnostic accuracy of mammography, clinical examination, US, and MR imaging in preoperative assessment of breast cancer 1. Radiology 2004, 233, 830-849. [CrossRef]

15. Mukherjee, S.D.; Hodgson, N.; Lovrics, P.J.; Dhamanaskar, K.; Minuk, T.; Chambers, S.; Sussman, J. A Retrospective Study Evaluating the Impact of Preoperative Breast MRI on Surgical Decision-Making in Young Patients ( $\leq 50$ Years) with Invasive Breast Cancer. Breast Cancer Basic Clin. Res. 2016, 10, 53. [CrossRef]

16. Johns Hopkins HealthCare. Medical Policy: Magnetic Resonance Imaging (MRI) of the Breast. Available online: https:/www.hopkinsmedicine.org/johns_hopkins_healthcare/downloads/Policies/cms_13_ 04_magnetic_resonance_imaging_2017.pdf (accessed on 14 July 2019).

17. Taif, S.A. Breast magnetic resonance imaging indications in current practice. Asian Pac. J. Cancer Prev. 2014, 15, 569-575. [CrossRef]

18. Gunawardena, D. Current Status of Breast MRI-Clinical applications. Sri Lanka J. Radiol. 2015, 1, 1-5. [CrossRef]

19. Menezes, G.L.; Knuttel, F.M.; Stehouwer, B.L.; Pijnappel, R.M.; van den Bosch, M.A. Magnetic resonance imaging in breast cancer: A literature review and future perspectives. World J. Clin. Oncol. 2014, 5, 61. [CrossRef] [PubMed]

20. Kuhl, C. The current status of breast MR imaging part I. Choice of technique, image interpretation, diagnostic accuracy, and transfer to clinical practice. Radiology 2007, 244, 356-378. [CrossRef] [PubMed]

21. Baltzer, P.A.; Dietzel, M.; Vag, T.; Burmeister, H.; Gajda, M.; Camara, O.; Pfleiderer, S.O.; Kaiser, W.A. Clinical MR Mammography: Impact of Hormonal Status on Background Enhancement and Diagnostic Accuracy. Röntgenstr 2011, 183, 441-447. [CrossRef] [PubMed]

22. Weinstock, C.; Campassi, C.; Goloubeva, O.; Wooten, K.; Kesmodel, S.; Bellevance, E.; Feigenberg, S.; Ioffe, O.; Tkaczuk, K.H. Breast magnetic resonance imaging (MRI) surveillance in breast cancer survivors. SpringerPlus 2015, 4, 459. [CrossRef] [PubMed]

23. American Society of Clinical Oncology. Breast MRI. Available online: http://www.cancer.net/navigatingcancer-care/diagnosing-cancer/tests-and-procedures/breast-mri (accessed on 18 February 2017).

24. Breast Cancer.org. Understanding Breast Calcifications. Available online: https://www.breastcancer.org/ symptoms/testing/types/mammograms/mamm_show/calcifications (accessed on 14 July 2019).

25. Heijblom, M.; Piras, D.; Brinkhuis, M.; Van Hespen, J.; Van den Engh, F.; Van der Schaaf, M.; Klaase, J.; van Leeuwen, T.; Steenbergen, W.; Manohar, S. Photoacoustic image patterns of breast carcinoma and comparisons with Magnetic Resonance Imaging and vascular stained histopathology. Sci. Rep. 2015, 5, 11778. [CrossRef]

26. Song, N. Quantitative Photoacoustic Tomography for Breast Cancer Screening; Ecole Centrale Marseille: Marseille, France, 2014.

27. Gupta, M.K.; Qin, R.-Y. Mechanism and its regulation of tumor-induced angiogenesis. World J. Gastroenterol. WJG 2003, 9, 1144. [CrossRef] [PubMed]

28. Carmeliet, P. Angiogenesis in life, disease and medicine. Nature 2005, 438, 932. [CrossRef] [PubMed]

29. Folkman, J. Tumor angiogenesis: Therapeutic implications. N. Engl. J. Med. 1971, 285, 1182-1186. [PubMed]

30. Wang, L.V. Photoacoustic imaging and spectroscopy; CRC Press: Boca Raton, FL, USA, 2009.

31. Tam, A.C. Applications of photoacoustic sensing techniques. Rev. Mod. Phys. 1986, 58, 381. [CrossRef]

32. Rosencwaig, A. Photoacoustics and photoacoustic spectroscopy; Wiley: Hoboken, NJ, USA, 1980.

33. Cox, B.; Laufer, J.G.; Arridge, S.R.; Beard, P.C. Quantitative spectroscopic photoacoustic imaging: A review. J. Biomed. Opt. 2012, 17, 0612021. [CrossRef] 
34. Steinberg, I.; Huland, D.M.; Vermesh, O.; Frostig, H.E.; Tummers, W.S.; Gambhir, S.S. Photoacoustic Clinical Imaging. Photoacoustics 2019, 14, 77-98. [CrossRef] [PubMed]

35. Heijblom, M.; Piras, D.; Engh, F.M.; Schaaf, M.; Klaase, J.M.; Steenbergen, W.; Manohar, S. The state of the art in breast imaging using the Twente Photoacoustic Mammoscope: Results from 31 measurements on malignancies. Eur. Radiol. 2016, 1-14. [CrossRef]

36. Heijblom, M.; Piras, D.; Maartens, E.; Huisman, E.J.; van den Engh, F.M.; Klaase, J.M.; Steenbergen, W.; Manohar, S. Appearance of breast cysts in planar geometry photoacoustic mammography using 1064-nm excitation. J. Biomed. Opt. 2013, 18, 126009. [CrossRef] [PubMed]

37. Neuschler, E.I.; Butler, R.; Young, C.A.; Barke, L.D.; Bertrand, M.L.; Böhm-Vélez, M.; Destounis, S.; Donlan, P.; Grobmyer, S.R.; Katzen, J. A Pivotal Study of Optoacoustic Imaging to Diagnose Benign and Malignant Breast Masses: A New Evaluation Tool for Radiologists. Radiology 2017, 287, 398-412. [CrossRef] [PubMed]

38. U.S. National Library of Medicine. The PIONEER-0 Study of the Imagio Breast Imaging System. Available online: https://clinicaltrials.gov/ct2/show/study/NCT01943916 (accessed on 6 March 2019).

39. Toi, M.; Asao, Y.; Matsumoto, Y.; Sekiguchi, H.; Yoshikawa, A.; Takada, M.; Kataoka, M.; Endo, T.; Kawaguchi-Sakita, N.; Kawashima, M. Visualization of tumor-related blood vessels in human breast by photoacoustic imaging system with a hemispherical detector array. Sci. Rep. 2017, 7. [CrossRef]

40. Kruger, R.A.; Lam, R.B.; Reinecke, D.R.; Del Rio, S.P.; Doyle, R.P. Photoacoustic angiography of the breast. Med. Phys. 2010, 37, 6096-6100. [CrossRef]

41. Beard, P. Biomedical photoacoustic imaging. Interface Focus 2011, 1, 602-631. [CrossRef]

42. Lammers, T.; Kiessling, F.; Hennink, W.E.; Storm, G. Drug targeting to tumors: Principles, pitfalls and (pre-) clinical progress. J. Control. Release 2012, 161, 175-187. [CrossRef]

43. Jain, R.K.; Safabakhsh, N.; Sckell, A.; Chen, Y.; Jiang, P.; Benjamin, L.; Yuan, F.; Keshet, E. Endothelial cell death, angiogenesis, and microvascular function after castration in an androgen-dependent tumor: Role of vascular endothelial growth factor. Proc. Natl. Acad. Sci. USA 1998, 95, 10820-10825. [CrossRef]

44. Yuan, F.; Salehi, H.A.; Boucher, Y.; Vasthare, U.S.; Tuma, R.F.; Jain, R.K. Vascular permeability and microcirculation of gliomas and mammary carcinomas transplanted in rat and mouse cranial windows. Cancer Res. 1994, 54, 4564-4568.

45. Danhier, F. To exploit the tumor microenvironment: Since the EPR effect fails in the clinic, what is the future of nanomedicine? J. Control. Release 2016, 244, 108-121. [CrossRef] [PubMed]

46. Stahl, T. Characterisation of Contrast Agents for Photoacoustic Imaging; UCL (University College London): London, UK, 2017.

47. Asao, Y.; Hashizume, Y.; Suita, T.; Nagae, K.-i.; Fukutani, K.; Sudo, Y.; Matsushita, T.; Kobayashi, S.; Tokiwa, M.; Yamaga, I. Photoacoustic mammography capable of simultaneously acquiring photoacoustic and ultrasound images. J. Biomed. Opt. 2016, 21, 116009. [CrossRef] [PubMed]

48. Menke, J. Photoacoustic breast tomography prototypes with reported human applications. Eur. Radiol. 2015, 25, 2205-2213. [CrossRef]

49. Zackrisson, S.; van de Ven, S.; Gambhir, S. Light in and sound out: Emerging translational strategies for photoacoustic imaging. Cancer Res. 2014, 74, 979-1004. [CrossRef]

50. Valluru, K.S.; Willmann, J.K. Clinical photoacoustic imaging of cancer. Ultrasonography 2016, 35, 267. [CrossRef]

51. Gargiulo, S.; Albanese, S.; Mancini, M. State-of-the-Art Preclinical Photoacoustic Imaging in Oncology: Recent Advances in Cancer Theranostics. Contrast Media Mol. Imaging 2019, 2019, 5080267. [CrossRef]

52. Manohar, S.; Dantuma, M. Current and future trends in photoacoustic breast imaging. Photoacoustics 2019, 16, 100134. [CrossRef]

53. Nyayapathi, N.; Xia, J. Photoacoustic imaging of breast cancer: A mini review of system design and image features. J. Biomed. Opt. 2019, 24, 121911. [CrossRef]

54. Esenaliev, R.O.; Karabutov, A.A.; Tittel, F.K.; Fornage, B.D.; Thomsen, S.L.; Stelling, C.; Oraevsky, A.A. Laser optoacoustic imaging for breast cancer diagnostics: Limit of detection and comparison with x-ray and ultrasound imaging. In Proceedings of the BiOS'97, Part of Photonics West, San Jose, CA, USA, 18 August 1997; pp. 71-82.

55. Web of Science. Available online: http://apps.webofknowledge.com/UA_GeneralSearch_input.do?product= UA\&SID=C3Dt5TrJjHRCHy7DaYF\&search_mode=GeneralSearch (accessed on 27 September 2018).

56. PubMed. Available online: https://www.ncbi.nlm.nih.gov/pubmed/ (accessed on 28 September 2018). 
57. IEEE. IEEE Xplore Digital Library. Available online: https://ieeexplore.iee.org/search/searchresult.jsp (accessed on 28 September 2018).

58. Nature. Available online: https://www.nature.com/search/advanced? (accessed on 28 September 2018).

59. Manohar, S.; Kharine, A.; van Hespen, J.C.; Steenbergen, W.; van Leeuwen, T.G. The Twente Photoacoustic Mammoscope: System overview and performance. Phys. Med. Biol. 2005, 50, 2543. [CrossRef]

60. Ku, G.; Fornage, B.D.; Jin, X.; Xu, M.; Hunt, K.K.; Wang, L.V. Thermoacoustic and photoacoustic tomography of thick biological tissues toward breast imaging. Technol. Cancer Res. Treat. 2005, 4, 559-565. [CrossRef]

61. Oraevsky, A.A.; Andreev, V.A.; Karabutov, A.A.; Fleming, R.D.; Gatalica, Z.; Singh, H.; Esenaliev, R.O. Laser optoacoustic imaging of the breast: Detection of cancer angiogenesis. In Proceedings of the BiOS'99 International Biomedical Optics Symposium, San Jose, CA, USA, 15 July 1999; pp. 352-363.

62. Andreev, V.G.; Karabutov, A.A.; Solomatin, S.V.; Savateeva, E.V.; Aleinikov, V.; Zhulina, Y.V.; Fleming, R.D.; Oraevsky, A.A. Optoacoustic tomography of breast cancer with arc-array transducer. In Proceedings of the BiOS 2000 The International Symposium on Biomedical Optics, San Jose, CA, USA, 19 May 2000; pp. 36-47.

63. Oraevsky, A.A.; Karabutov, A.A.; Solomatin, S.V.; Savateeva, E.V.; Andreev, V.A.; Gatalica, Z.; Singh, H.; Fleming, R.D. Laser optoacoustic imaging of breast cancer in vivo. In Proceedings of the BiOS 2001 The International Symposium on Biomedical Optics, San Jose, CA, USA, 15 June 2001; pp. 6-15.

64. Oraevsky, A.A.; Savateeva, E.V.; Solomatin, S.V.; Karabutov, A.A.; Andreev, V.G.; Gatalica, Z.; Khamapirad, T.; Henrichs, P.M. Optoacoustic imaging of blood for visualization and diagnostics of breast cancer. In Proceedings of the International Symposium on Biomedical Optics, San Jose, CA, USA, 10 June 2002; pp. 81-94.

65. Ermilov, S.A.; Conjusteau, A.; Mehta, K.; Lacewell, R.; Henrichs, P.M.; Oraevsky, A.A. 128-channel laser optoacoustic imaging system (LOIS-128) for breast cancer diagnostics. In Proceedings of the Biomedical Optics, San Jose, CA, USA, 6 March 2006; pp. 608609-608612.

66. Ermilov, S.A.; Khamapirad, T.; Conjusteau, A.; Leonard, M.H.; Lacewell, R.; Mehta, K.; Miller, T.; Oraevsky, A.A. Laser optoacoustic imaging system for detection of breast cancer. J. Biomed. Opt. 2009, 14, 024007. [CrossRef] [PubMed]

67. Jose, J.; Manohar, S.; Kolkman, R.G.; Steenbergen, W.; van Leeuwen, T.G. Imaging of tumor vasculature using Twente photoacoustic systems. J. Biophotonics 2009, 2, 701-717. [CrossRef]

68. Xia, W.; Piras, D.; Singh, M.K.; van Hespen, J.C.; van Leeuwen, T.G.; Steenbergen, W.; Manohar, S. Design and evaluation of a laboratory prototype system for $3 \mathrm{D}$ photoacoustic full breast tomography. Biomed. Opt. Express 2013, 4, 2555-2569. [CrossRef] [PubMed]

69. Pramanik, M.; Ku, G.; Li, C.; Wang, L.V. Design and evaluation of a novel breast cancer detection system combining both thermoacoustic (TA) and photoacoustic (PA) tomography. Med. Phys. 2008, 35, 2218-2223. [CrossRef] [PubMed]

70. Ke, H.; Erpelding, T.N.; Jankovic, L.; Liu, C.; Wang, L.V. Performance characterization of an integrated ultrasound, photoacoustic, and thermoacoustic imaging system. J. Biomed. Opt. 2012, 17, 0560101-0560106. [CrossRef] [PubMed]

71. Ye, F.; Yang, S.; Xing, D. Three-dimensional photoacoustic imaging system in line confocal mode for breast cancer detection. Appl. Phys. Lett. 2010, 97, 213702. [CrossRef]

72. Xi, L.; Li, X.; Yao, L.; Grobmyer, S.; Jiang, H. Design and evaluation of a hybrid photoacoustic tomography and diffuse optical tomography system for breast cancer detection. Med. Phys. 2012, 39, 2584-2594. [CrossRef]

73. Kruger, R.A.; Kuzmiak, C.M.; Lam, R.B.; Reinecke, D.R.; Del Rio, S.P.; Steed, D. Dedicated 3D photoacoustic breast imaging. Med. Phys. 2013, 40, 113301. [CrossRef]

74. Bharathiraja, S.; Manivasagan, P.; Quang Bui, N.; Oh, Y.-O.; Lim, I.G.; Park, S.; Oh, J. Cytotoxic Induction and Photoacoustic Imaging of Breast Cancer Cells Using Astaxanthin-Reduced Gold Nanoparticles. Nanomaterials 2016, 6, 78. [CrossRef]

75. Wilson, K.E.; Bachawal, S.V.; Tian, L.; Willmann, J.K. Multiparametric spectroscopic photoacoustic imaging of breast cancer development in a transgenic mouse model. Theranostics 2014, 4, 1062-1071. [CrossRef]

76. Zhang, T.; Cui, H.; Fang, C.-Y.; Jo, J.; Yang, X.; Chang, H.-C.; Forrest, M.L. In vivo photoacoustic imaging of breast cancer tumor with HER2-targeted nanodiamonds. In Proceedings of the SPIE NanoScience+ Engineering, San Diego, CA, USA, 20 September 2013; p. 881504. 
77. Balasundaram, G.; Ho, C.J.H.; Li, K.; Driessen, W.; Dinish, U.; Wong, C.L.; Ntziachristos, V.; Liu, B.; Olivo, M. Molecular photoacoustic imaging of breast cancer using an actively targeted conjugated polymer. Int. J. Nanomed. 2015, 10, 387. [CrossRef]

78. Xiao, W.; Li, Y.; Hu, C.; Huang, Y.; He, Q.; Gao, H. Melanin-originated carbonaceous dots for triple negative breast cancer diagnosis by fluorescence and photoacoustic dual-mode imaging. J. Colloid Interface Sci. 2017, 497, 226-232. [CrossRef]

79. Xia, J.; Feng, G.; Xia, X.; Hao, L.; Wang, Z. NH4HCO3 gas-generating liposomal nanoparticle for photoacoustic imaging in breast cancer. Int. J. Nanomed. 2017, 12, 1803. [CrossRef]

80. Wilson, K.E.; Bachawal, S.V.; Abou-Elkacem, L.; Jensen, K.; Machtaler, S.; Tian, L.; Willmann, J.K. Spectroscopic Photoacoustic Molecular Imaging of Breast Cancer using a B7-H3-targeted ICG Contrast Agent. Theranostics 2017, 7, 1463. [CrossRef]

81. Song, K.H.; Stein, E.W.; Margenthaler, J.A.; Wang, L.V. Noninvasive photoacoustic identification of sentinel lymph nodes containing methylene blue in vivo in a rat model. J. Biomed. Opt. 2008, 13, 054033. [CrossRef]

82. Song, K.H.; Kim, C.; Cobley, C.M.; Xia, Y.; Wang, L.V. Near-infrared gold nanocages as a new class of tracers for photoacoustic sentinel lymph node mapping on a rat model. Nano Lett. 2008, 9, 183-188. [CrossRef] [PubMed]

83. Song, K.H.; Kim, C.; Maslov, K.; Wang, L.V. Noninvasive in vivo spectroscopic nanorod-contrast photoacoustic mapping of sentinel lymph nodes. Eur. J. Radiol. 2009, 70, 227-231. [CrossRef] [PubMed]

84. Song, L.; Kim, C.; Maslov, K.; Shung, K.K.; Wang, L.V. High-speed dynamic 3D photoacoustic imaging of sentinel lymph node in a murine model using an ultrasound array. Med. Phys. 2009, 36, 3724-3729. [CrossRef] [PubMed]

85. Pramanik, M.; Song, K.H.; Swierczewska, M.; Green, D.; Sitharaman, B.; Wang, L.V. In vivo carbon nanotube-enhanced non-invasive photoacoustic mapping of the sentinel lymph node. Phys. Med. Biol. 2009, 54, 3291. [CrossRef] [PubMed]

86. Pan, D.; Pramanik, M.; Senpan, A.; Ghosh, S.; Wickline, S.A.; Wang, L.V.; Lanza, G.M. Near infrared photoacoustic detection of sentinel lymph nodes with gold nanobeacons. Biomaterials 2010, 31, 4088-4093. [CrossRef]

87. Akers, W.J.; Kim, C.; Berezin, M.; Guo, K.; Fuhrhop, R.; Lanza, G.M.; Fischer, G.M.; Daltrozzo, E.; Zumbusch, A.; Cai, X. Noninvasive photoacoustic and fluorescence sentinel lymph node identification using dye-loaded perfluorocarbon nanoparticles. ACS Nano 2010, 5, 173-182. [CrossRef] [PubMed]

88. Kim, C.; Erpelding, T.N.; Jankovic, L.; Pashley, M.D.; Wang, L.V. Deeply penetrating in vivo photoacoustic imaging using a clinical ultrasound array system. Biomed. Opt. Express 2010, 1, 278-284. [CrossRef]

89. Kim, C.; Song, K.H.; Gao, F.; Wang, L.V. Sentinel lymph nodes and lymphatic vessels: Noninvasive dual-modality in vivo mapping by using indocyanine green in rats-volumetric spectroscopic photoacoustic imaging and planar fluorescence imaging 1. Radiology 2010, 255, 442-450. [CrossRef] [PubMed]

90. Kim, C.; Erpelding, T.N.; Maslov, K.; Jankovic, L.; Akers, W.J.; Song, L.; Achilefu, S.; Margenthaler, J.A.; Pashley, M.D.; Wang, L.V. Handheld array-based photoacoustic probe for guiding needle biopsy of sentinel lymph nodes. J. Biomed. Opt. 2010, 15, 046010. [CrossRef] [PubMed]

91. Erpelding, T.N.; Kim, C.; Pramanik, M.; Jankovic, L.; Maslov, K.; Guo, Z.; Margenthaler, J.A.; Pashley, M.D.; Wang, L.V. Sentinel lymph nodes in the rat: Noninvasive photoacoustic and US imaging with a clinical US system. Radiology 2010, 256, 102-110. [CrossRef] [PubMed]

92. Pan, D.; Cai, X.; Yalaz, C.; Senpan, A.; Omanakuttan, K.; Wickline, S.A.; Wang, L.V.; Lanza, G.M. Photoacoustic sentinel lymph node imaging with self-assembled copper neodecanoate nanoparticles. ACS Nano 2012, 6, 1260-1267. [CrossRef]

93. Luke, G.P.; Bashyam, A.; Homan, K.A.; Makhija, S.; Chen, Y.-S.; Emelianov, S.Y. Silica-coated gold nanoplates as stable photoacoustic contrast agents for sentinel lymph node imaging. Nanotechnology 2013, 24, 455101. [CrossRef]

94. Grootendorst, D.J.; Jose, J.; Fratila, R.M.; Visscher, M.; Velders, A.H.; Ten Haken, B.; Van Leeuwen, T.G.; Steenbergen, W.; Manohar, S.; Ruers, T.J. Evaluation of superparamagnetic iron oxide nanoparticles $\left(\right.$ Endorem ${ }^{\circledR}$ ) as a photoacoustic contrast agent for intra-operative nodal staging. Contrast Media Mol. Imaging 2013, 8, 83-91. [CrossRef] 
95. Liu, X.; Law, W.C.; Jeon, M.; Wang, X.; Liu, M.; Kim, C.; Prasad, P.N.; Swihart, M.T. Cu2-xSe nanocrystals with localized surface plasmon resonance as sensitive contrast agents for in vivo photoacoustic imaging: Demonstration of sentinel lymph node mapping. Adv. Healthc. Mater. 2013, 2, 952-957.

96. Koo, J.; Jeon, M.; Oh, Y.; Kang, H.W.; Kim, J.; Kim, C.; Oh, J. In vivo non-ionizing photoacoustic mapping of sentinel lymph nodes and bladders with ICG-enhanced carbon nanotubes. Phys. Med. Biol. 2012, 57, 7853. [CrossRef]

97. Lee, C.; Kim, J.; Zhang, Y.; Jeon, M.; Liu, C.; Song, L.; Lovell, J.F.; Kim, C. Dual-color photoacoustic lymph node imaging using nanoformulated naphthalocyanines. Biomaterials 2015, 73, 142-148. [CrossRef] [PubMed]

98. Yang, L.; Cheng, J.; Chen, Y.; Yu, S.; Liu, F.; Sun, Y.; Chen, Y.; Ran, H. Phase-transition nanodroplets for real-time photoacoustic/ultrasound dual-modality imaging and photothermal therapy of sentinel lymph node in breast cancer. Sci. Rep. 2017, 7, 45213. [CrossRef] [PubMed]

99. Sivasubramanian, K.; Periyasamy, V.; Pramanik, M. Hand-held Clinical Photoacoustic Imaging System for Real-time Non-invasive Small Animal Imaging. 2017. Available online: https://www.jove.com/video/56649/ hand-held-clinical-photoacoustic-imaging-system-for-real-time-non (accessed on 21 January 2020).

100. Cha, M.G.; Lee, S.; Park, S.; Kang, H.; Lee, S.G.; Jeong, C.; Lee, Y.-S.; Kim, C.; Jeong, D.H. A dual modal silver bumpy nanoprobe for photoacoustic imaging and SERS multiplexed identification of in vivo lymph nodes. Nanoscale 2017, 9, 12556-12564. [CrossRef] [PubMed]

101. Kim, G.R.; Kang, J.; Kwak, J.Y.; Chang, J.H.; Kim, S.I.; Youk, J.H.; Moon, H.J.; Kim, M.J.; Kim, E.-K. Photoacoustic imaging of breast microcalcifications: A preliminary study with 8-gauge core-biopsied breast specimens. PLoS ONE 2014, 9, e105878. [CrossRef] [PubMed]

102. Wong, T.T.; Zhang, R.; Hai, P.; Zhang, C.; Pleitez, M.A.; Aft, R.L.; Novack, D.V.; Wang, L.V. Fast label-free multilayered histology-like imaging of human breast cancer by photoacoustic microscopy. Sci. Adv. 2017, 3, e1602168. [CrossRef] [PubMed]

103. Manohar, S.; Vaartjes, S.E.; van Hespen, J.C.; Klaase, J.M.; van den Engh, F.M.; Steenbergen, W.; Van Leeuwen, T.G. Initial results of in vivo non-invasive cancer imaging in the human breast using near-infrared photoacoustics. Opt. Express 2007, 15, 12277-12285. [CrossRef]

104. Menezes, G.L.; Pijnappel, R.M.; Meeuwis, C.; Bisschops, R.; Veltman, J.; Lavin, P.T.; van de Vijver, M.J.; Mann, R.M. Downgrading of Breast Masses Suspicious for Cancer by Using Optoacoustic Breast Imaging. Radiology 2018, 288, 355-365. [CrossRef]

105. U.S. National Library of Medicine. Imaging with Opto-acoustics to downgrade BI-RADS classification relative to other Diagnostic Methodologies (MAESTRO). Available online: https://clinicaltrials.gov/ct2/show/ record/NCT02364388 (accessed on 6 March 2019).

106. Lin, L.; Hu, P.; Shi, J.; Appleton, C.M.; Maslov, K.; Li, L.; Zhang, R.; Wang, L.V. Single-breath-hold photoacoustic computed tomography of the breast. Nat. Commun. 2018, 9, 2352. [CrossRef]

107. Garcia-Uribe, A.; Erpelding, T.N.; Krumholz, A.; Ke, H.; Maslov, K.; Appleton, C.; Margenthaler, J.A.; Wang, L.V. Dual-modality photoacoustic and ultrasound imaging system for noninvasive sentinel lymph node detection in patients with breast cancer. Sci. Rep. 2015, 5. [CrossRef]

108. Kitai, T.; Torii, M.; Sugie, T.; Kanao, S.; Mikami, Y.; Shiina, T.; Toi, M. Photoacoustic mammography: Initial clinical results. Breast Cancer 2014, 21, 146-153. [CrossRef]

109. Fakhrejahani, E.; Torii, M.; Kitai, T.; Kanao, S.; Asao, Y.; Hashizume, Y.; Mikami, Y.; Yamaga, I.; Kataoka, M.; Sugie, T. Clinical report on the first prototype of a photoacoustic tomography system with dual illumination for breast cancer imaging. PLoS ONE 2015, 10, e0139113. [CrossRef]

110. Li, X.; Heldermon, C.D.; Yao, L.; Xi, L.; Jiang, H. High resolution functional photoacoustic tomography of breast cancer. Med. Phys. 2015, 42, 5321-5328. [CrossRef]

111. Zalev, J.; Clingman, B.; Herzog, D.; Miller, T.; Ulissey, M.; Stavros, A.T.; Oraevsky, A.; Lavin, P.; Kist, K.; Dornbluth, N.C. Opto-acoustic image fusion technology for diagnostic breast imaging in a feasibility study. In Proceedings of the SPIE Medical Imaging, Orlando, FL, USA, 17 March 2015; p. 941909.

112. Neuschler, E.I.; Lavin, P.T.; Tucker, F.L.; Barke, L.D.; Bertrand, M.L.; Böhm-Vélez, M.; Destounis, S.; Dogan, B.E.; Grobmyer, S.R.; Katzen, J. Downgrading and upgrading gray-scale ultrasound BI-RADS categories of benign and malignant masses with optoacoustics: A pilot study. Am. J. Roentgenol. 2018, 211, 689-700. [CrossRef] [PubMed] 
113. Menezes, G.L.; Mann, R.M.; Meeuwis, C.; Bisschops, B.; Veltman, J.; Lavin, P.T.; van de Vijver, M.J.; Pijnappel, R.M. Optoacoustic imaging of the breast: Correlation with histopathology and histopathologic biomarkers. Eur. Radiol. 2019, 1-13. [CrossRef] [PubMed]

114. Dogan, B.E.; Menezes, G.L.; Butler, R.S.; Neuschler, E.I.; Aitchison, R.; Lavin, P.T.; Tucker, F.L.; Grobmyer, S.R.; Otto, P.M.; Stavros, A.T. Optoacoustic imaging and gray-scale US features of breast cancers: Correlation with molecular subtypes. Radiology 2019, 292, 564-572. [CrossRef] [PubMed]

115. Piras, D.; Xia, W.; Steenbergen, W.; van Leeuwen, T.G.; Manohar, S. Photoacoustic imaging of the breast using the twente photoacoustic mammoscope: Present status and future perspectives. IEEE J. Sel. Top. Quantum Electron. 2010, 16, 730-739. [CrossRef]

116. Heijblom, M.; Piras, D.; Ten Tije, E.; Xia, W.; Van Hespen, J.; Klaase, J.; Van den Engh, F.; Van Leeuwen, T.; Steenbergen, W.; Manohar, S. Breast imaging using the Twente Photoacoustic Mammoscope (PAM): New clinical measurements. In Proceedings of the European Conference on Biomedical Optics, Munich Germany, 22-26 May 2011; p. 80870N.

117. Heijblom, M.; Piras, D.; Xia, W.; Van Hespen, J.; Klaase, J.; Van den Engh, F.; Van Leeuwen, T.; Steenbergen, W.; Manohar, S. Visualizing breast cancer using the Twente photoacoustic mammoscope: What do we learn from twelve new patient measurements? Opt. Express 2012, 20, 11582-11597. [CrossRef]

118. Erguvan-Dogan, B.; Whitman, G.J.; Kushwaha, A.C.; Phelps, M.J.; Dempsey, P.J. Bi-RADS-MRI: A primer. Am. J. Roentgenol. 2006, 187, W152-W160. [CrossRef]

119. Oraevsky, A. 3D optoacoustic tomography: From molecular targets in mouse models to functional imaging of breast cancer. In Proceedings of the conference on Lasers and Electro-Optics (CLEO), San Jose, CA, USA, 8-13 June 2014; pp. 1-2.

120. Oraevsky, A.; Su, R.; Nguyen, H.; Moore, J.; Lou, Y.; Bhadra, S.; Forte, L.; Anastasio, M.; Yang, W. Full-View 3d Imaging System for Functional and Anatomical Screening of the Breast; SPIE: San Francisco, CA, USA, 11 April 2018; Volume 10494.

121. Raikhlin, A.; Curpen, B.; Warner, E.; Betel, C.; Wright, B.; Jong, R. Breast MRI as an adjunct to mammography for breast cancer screening in high-risk patients: Retrospective review. Am. J. Roentgenol. 2015, 204, 889-897. [CrossRef]

122. Becker, A.; Masthoff, M.; Claussen, J.; Ford, S.J.; Roll, W.; Burg, M.; Barth, P.J.; Heindel, W.; Schäfers, M.; Eisenblätter, M. Multispectral optoacoustic tomography of the human breast: Characterisation of healthy tissue and malignant lesions using a hybrid ultrasound-optoacoustic approach. Eur. Radiol. 2017, 28, 602-609. [CrossRef] [PubMed]

123. Diot, G.; Metz, S.; Noske, A.; Liapis, E.; Schroeder, B.; Ovsepian, S.V.; Meier, R.; Rummeny, E.; Ntziachristos, V. Multispectral Optoacoustic Tomography (MSOT) of Human Breast Cancer. Clin. Cancer Res. 2017, 23, 6912-6922. [CrossRef] [PubMed]

124. Abeyakoon, O.; Morscher, S.; Dalhaus, N.; Ford, S.J.; Mendichovszky, I.A.; Manavaki, R.; Wallis, M.; Moyle, P.; Woitek, R.; Patterson, A. Optoacoustic Imaging Detects Hormone-Related Physiological Changes of Breast Parenchyma. Ultraschall Med.-Eur. J. Ultrasound 2019, 40, 757-763. [CrossRef] [PubMed]

125. Li, X.; Heldermon, C.; Jiang, H. Monitoring neoadjuvant chemotherapy in breast cancer using quantitative photoacoustic tomography. In Proceedings of the Biomedical Optics, Miami, FL, USA, 26-30 April 2014; p. BS3A. 66.

126. Hysi, E.; Wirtzfeld, L.A.; May, J.P.; Undzys, E.; Li, S.-D.; Kolios, M.C. Photoacoustic signal characterization of cancer treatment response: Correlation with changes in tumor oxygenation. Photoacoustics 2017, 5, 25-35. [CrossRef]

127. Heijblom, M.; Steenbergen, W.; Manohar, S. Clinical photoacoustic breast imaging: The Twente experience. IEEE Pulse 2015, 6, 42-46. [CrossRef]

128. Yamaga, I.; Kawaguchi-Sakita, N.; Asao, Y.; Matsumoto, Y.; Yoshikawa, A.; Fukui, T.; Takada, M.; Kataoka, M.; Kawashima, M.; Fakhrejahani, E. Vascular branching point counts using photoacoustic imaging in the superficial layer of the breast: A potential biomarker for breast cancer. Photoacoustics 2018, 11, 6-13. [CrossRef]

(C) 2020 by the authors. Licensee MDPI, Basel, Switzerland. This article is an open access article distributed under the terms and conditions of the Creative Commons Attribution (CC BY) license (http://creativecommons.org/licenses/by/4.0/). 